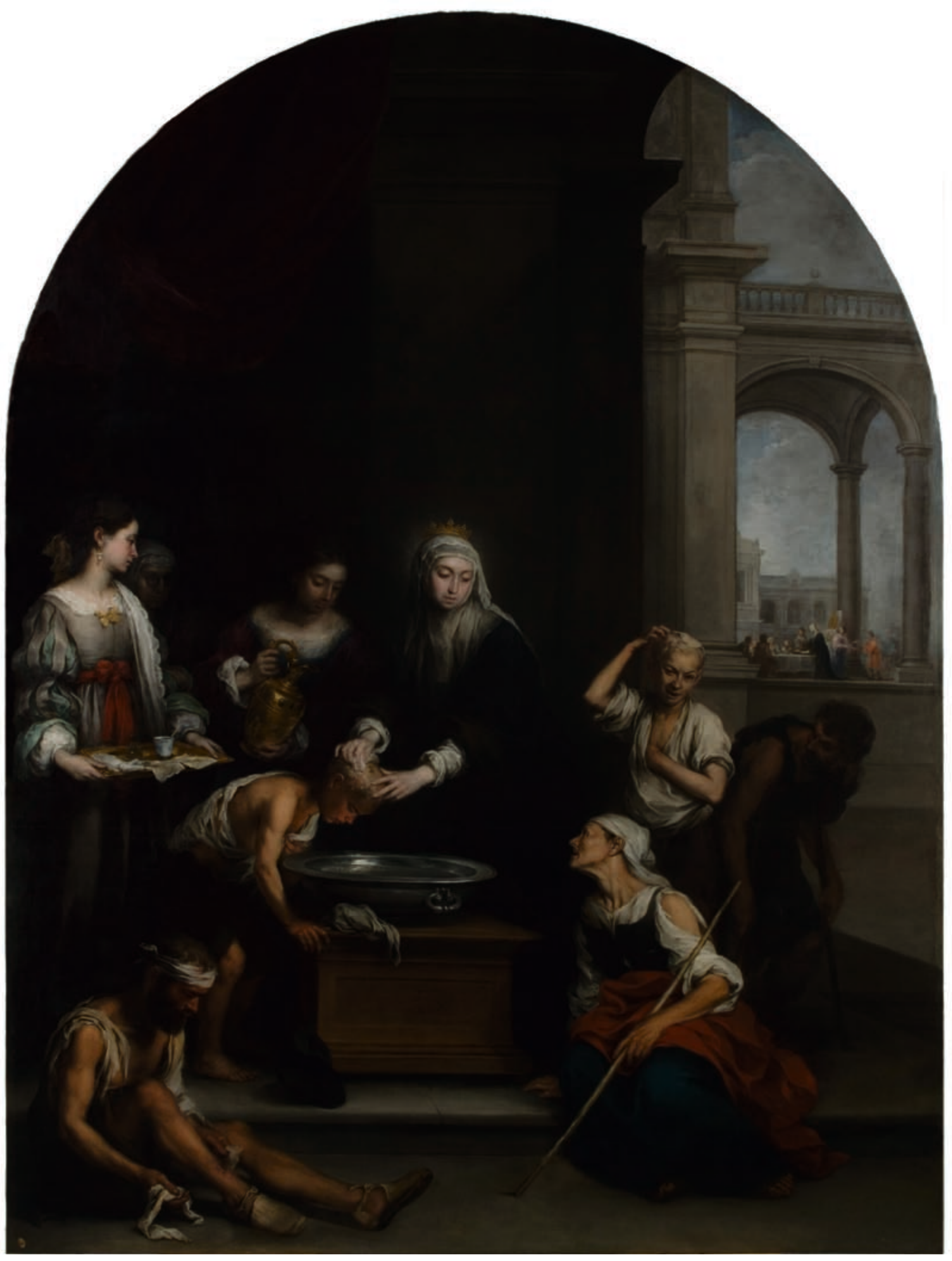




\section{Recuperación de una obra de Bartolomé Esteban Murillo: Santa Isabel de Hungría curando a los tiñosos}

Amalia Cansino Cansino, Gabriel Ferreras Romero, Lourdes Martín

García, Centro de Intervención del IAPH

\section{Resumen}

El Centro de Intervención del Instituto Andaluz del Patrimonio Histórico ha desarrollado el proyecto de investigación y restauración de una de las obras más conocidas de Bartolomé Esteban Murillo, Santa Isabel de Hungría curando a los tiñosos, pintura al óleo sobre lienzo de $345 \times 228 \mathrm{~cm}$ ( $\mathrm{h} \times$ a) realizada en 1672 y que pertenece al conjunto iconográfico que encargó Miguel Mañara para decorar la Iglesia del Señor San Jorge de la Hermandad de la Santa Caridad de Sevilla.

Debido al expolio francés, la obra faltó de Sevilla desde 1811 a 1939, y ha permanecido hasta nuestros dias en malas condiciones de conservación. Por ello, muchas generaciones de visitantes no han conocido en todo su esplendor la calidad de esta magnífica obra de Murillo, que presentaba apariencia amarillenta y aspecto casi plano, debido a la cantidad de elementos añadidos a la capa pictórica a lo largo de su historia.

El trabajo de restauración ha permitido realizar una investigación detallada de este bien y conocer las circunstancias concretas que han afectado a su historia material, a la que corresponden las alteraciones que presentaba. Con la actuación de conservación-restauración recientemente finalizada, la obra ha recuperado luminosidad y perspectiva, siendo por tanto más cercana en su estado actual a la que plasmó Murillo en el momento de su ejecución.

\section{Palabras clave}

Centro de Intervención / Conservación / Historia / Hospital de la Santa Caridad / Iglesia de San Jorge / Instituto Andaluz del Patrimonio Histórico / Intervención / Investigación / Lienzo / Murillo, Bartolomé Esteban / Óleo / Patrimonio mueble / Pinturas / Santa Isabel de Hungria curando a los tiñosos / Sevilla / 1672 


\section{ORIGEN DE LA OBRA}

La obra denominada Santa Isabel de Hungría curando a los tiñosos, pintada por Bartolomé Esteban Murillo, fue encargada por Miguel Mañara y Vicentelo de Leca, hermano mayor de la Hermandad de la Santa Caridad de Sevilla. Forma parte integrante de la ampliación del programa iconográfico referido a las siete obras de misericordia de la Iglesia del Señor San Jorge del Hospital de la Santa Caridad. Dicha pintura constituye la escena central y única, ubicada en el primer retablo-marco del lado de la Epístola del templo. Asimismo, consta documentalmente en un Libro de Cabildos de la Hermandad, con fecha 28 de diciembre de 1672, que se pagó por el lienzo "ocho mil cuatrocientos veinte reales de vellón" a su autor ${ }^{1}$.

\section{HISTORIA MATERIAL}

Desde 1672 el lienzo estuvo ubicado en su altar hasta 1810, año en que es trasladado al Alcázar de Sevilla por orden del mariscal Soult. El pintor Joaquín Cortés realizó anteriormente varias copias en el Hospital de la Caridad, ordenadas por el rey Carlos IV, con la intención de ser sustituidas las obras originales de Murillo y enviarlas al Real Museo de Madrid, proyecto que no se llevó a cabo, pues las obras originales se quedaron en Sevilla, llevándose las copias que en la actualidad se conservan en Patrimonio Nacional. En concreto la copia de Santa Isabel

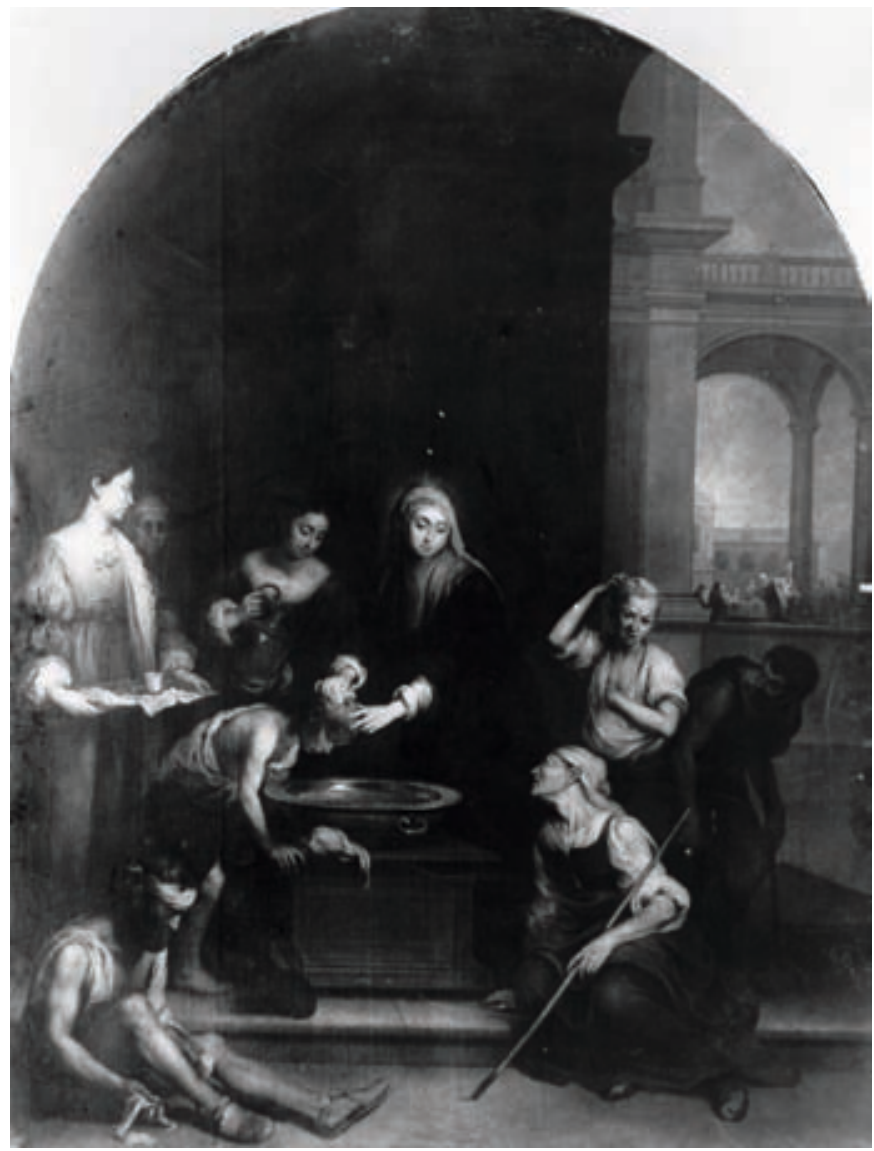

Copia de la obra de Murillo realizada por el pintor Joaquín $M^{a}$ Cortés Caballero. Fuente: Patrimonio Nacional se encuentra en el Palacio de Oriente en la planta baja, sala 2, dependencia del Príncipe².

El 1 de febrero de 1810, varias columnas de tropas napoleónicas encabezadas por el mariscal Victor Claude Perrin entran en Sevilla sin encontrar resistencia. Hacia las 11 de la mañana del mismo día, llegan a Sevilla los primeros Cuerpos de la División del Mediodía, al mando del mariscal Soult, Duque de Dalmacia (MORENO ALONSO, 1995: 99). Este mismo año la obra es objeto del expolio llevado a cabo por las mencionadas tropas de Napoleón.

Anteriormente, en 1809, el ministro y secretario de estado, Mariano Luis de Urquijo, establece una Real Orden a través de la cual se estipula que "se formaria una colección como regalo a Napoleón, donde siendo un monumento a la gloria de los artistas españoles, sirviera como prenda de unión de las dos grandes naciones". De esta manera el mencionado expolio queda encubierto ${ }^{3} y$, a fines del mes de febrero de 1810, el lienzo es trasladado, junto a otras siete obras de Murillo, al Alcázar de Sevilla, donde permanecen depositadas en la Sala primera con el número $1^{4}$.

El 12 de enero de 1811, siendo gobernador civil el mariscal Soult, se envian desde Sevilla, dirección a Madrid, los ocho Murillos son sustraidos del Hospital de la Santa Caridad, entre ellos Santa Isabel de Hungría curando a los tiñosos.

Al llegar a la Corte es almacenado en el Convento del Rosario de Madrid, y desde alli se lleva a Francia, donde es restaurado por primera vez y se le da formato rectangular, añadiéndole en su zona superior unas enjutas doradas. Posteriormente este lienzo será cedido al Emperador Napoleón Bonaparte para el museo del Louvre, junto a los dos cuadros procedentes de Santa María la Blanca de Sevilla, El Sueño del Patricio y La visita del patricio Juan con su esposa al pontífice Liberio, además de La Apoteosis de Santo Tomás de Aquino de Zurbarán.

Una vez en París permanece en dicho museo hasta 1815, momento en el que, pese a la oposición de Vivant Denon, director de la institución, la obra es devuelta vía maritima desde Amberes a bordo de la fragata holandesa Amstel. Tras llegar al puerto de Valencia es trasladada y depositada en la Real Academia de Bellas Artes de San Fernando de Madrid.

Entre 1901 y 1902 la custodia es concedida al Museo del Prado, donde estuvo expuesta en la denominada sala de Murillo hasta 1939, cuando por orden del Ministerio de Educación, y gracias a las gestiones llevadas a cabo por Joaquín Romero Murube, Comisario de Arte del Ayuntamiento de Sevilla ${ }^{5}$, la obra regresa a la capital hispalense. Según el Libro de Actas de 7 de noviembre de 1939, la obra es recibida en el Ayuntamiento y entregada a los miembros de la Hermandad en acto público. Es probable que desde esta fecha el lienzo ocupara su ubicación original en el retablo del primer altar del lado de la Epistola hasta su reciente intervención en el Instituto Andaluz del Patrimonio Histórico. 


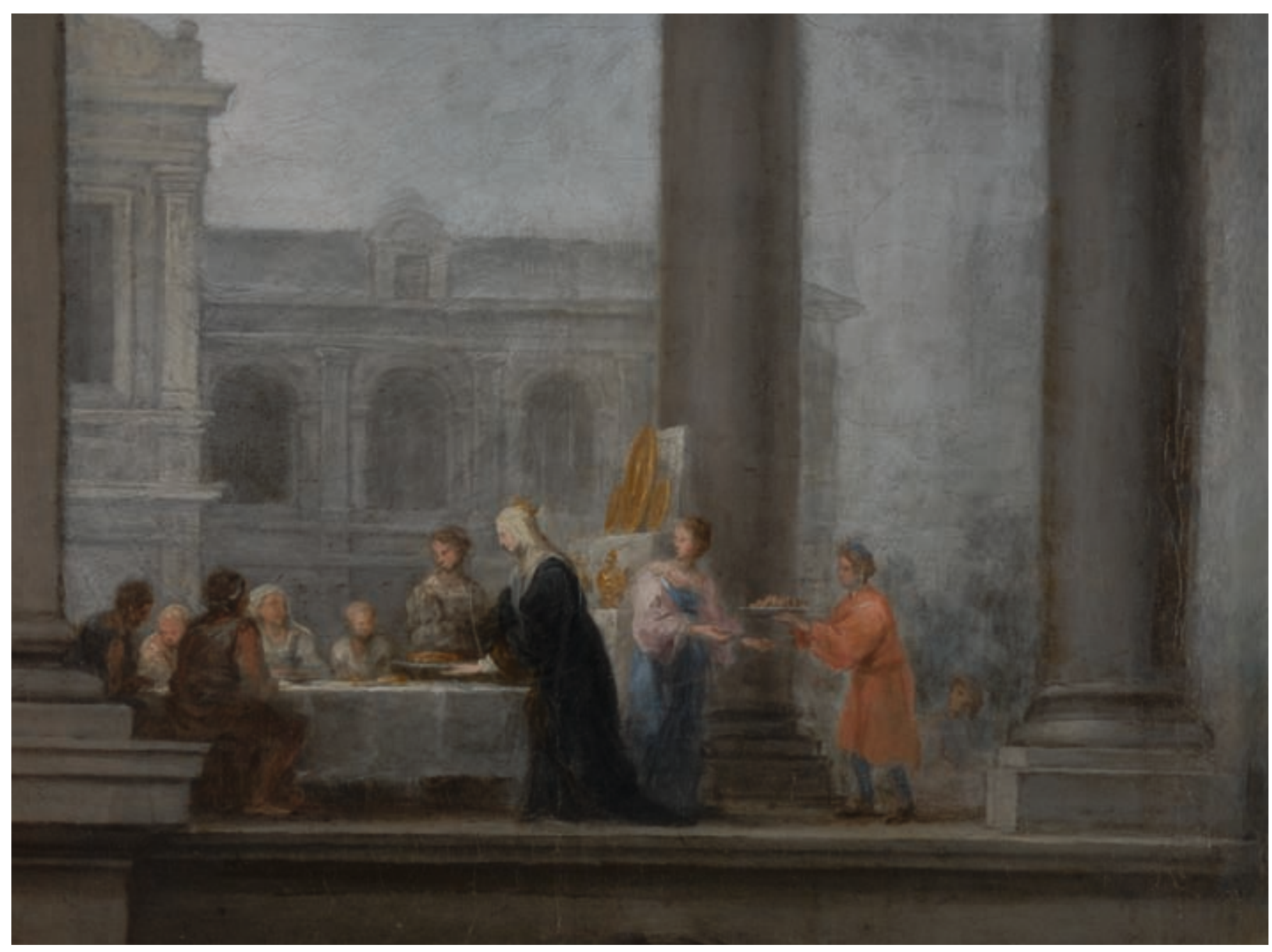

Detalle de la escena representada en el fondo de la obra. Foto: Eugenio Fernández Ruiz, IAPH

\section{Restauraciones}

Es posible afirmar que la obra ha sido intervenida al menos en dos ocasiones. La primera de ellas durante su estancia en París, entre 1811 y 1815, para subsanar los daños provocados en el lienzo por los avatares de su traslado desde España a Francia y darle formato rectangular. Entre 1815 y 1939, una vez en madrid, el lienzo es de nuevo intervenido, debido a su mal estado, pues en la Academia de San Fernando estuvo como olvidado y probablemente la segunda vez que se restaura sería en el Museo del Prado, cuando en abril de 1910 se inaugura, por iniciativa de José Villegas Cordero, pintor sevillano y director del museo en esos años, la sala dedicada a Murillo y nueva decoración gracias al donativo de la futura condesa de Parcent (W.AA., 2001: 91).

\section{Hagiografía}

La vida de Santa Isabel fue corta pero muy intensa, pues sólo vivió 24 años. Era hija de rey Andrés II de Hungría y Gertrudis de Andech-Meran. En 1221, con 14 años, contrajo matrimonio con Luis IV, príncipe de Turingia. A la muerte de su esposo, en 1227, decidió llevar una vida ascética, dedicándose a realizar obras de misericordia o caridad. Para ello construyó un hospital para pobres y tiñosos o leprosos en Marburgo (Alemania), atendiendo personalmente a los enfermos. En 1228 tomó el hábito de la orden tercera de San Francisco y murió en 1231. Fue canonizada en 1235 por el Papa Gregorio IX convirtiéndose en la patrona de los terciarios franciscanos (RÈAU, 1997: 122-123).

\section{Iconografía}

En la escena principal del cuadro se representa a la Santa vestida con el hábito de la orden terciaria franciscana, ennoblecido con un forro de piel de visón. Asimismo, aparece con la cabeza cubierta con velo y toca monjil aunque coronada, como símbolo de su condición real y está acompañada por sus damas, que portan objetos de un ajuar noble. La más cercana a la Santa porta una jarra de metal con la que vierte el agua en la jofaina donde se cura a los enfermos, y otra porta bandeja con vendas y jicara de porcelana azul y blanca con ungüentos.

En el segundo plano la Santa porta en sus manos una bandeja llena de alimentos y es de nuevo asistida por las mismas doncellas más un criado vestido a la turca, donde aparece también dando de comer a los mismos pobres y enfermos de la escena central, que la aguardan sentados en la mesa. La escena transcurre bajo un monumental pórtico renacentista. Murillo ilustra a través de su composición dos de las Reglas establecidas por Miguel Mañara para los Hermanos de la Santa Caridad (Reglas 


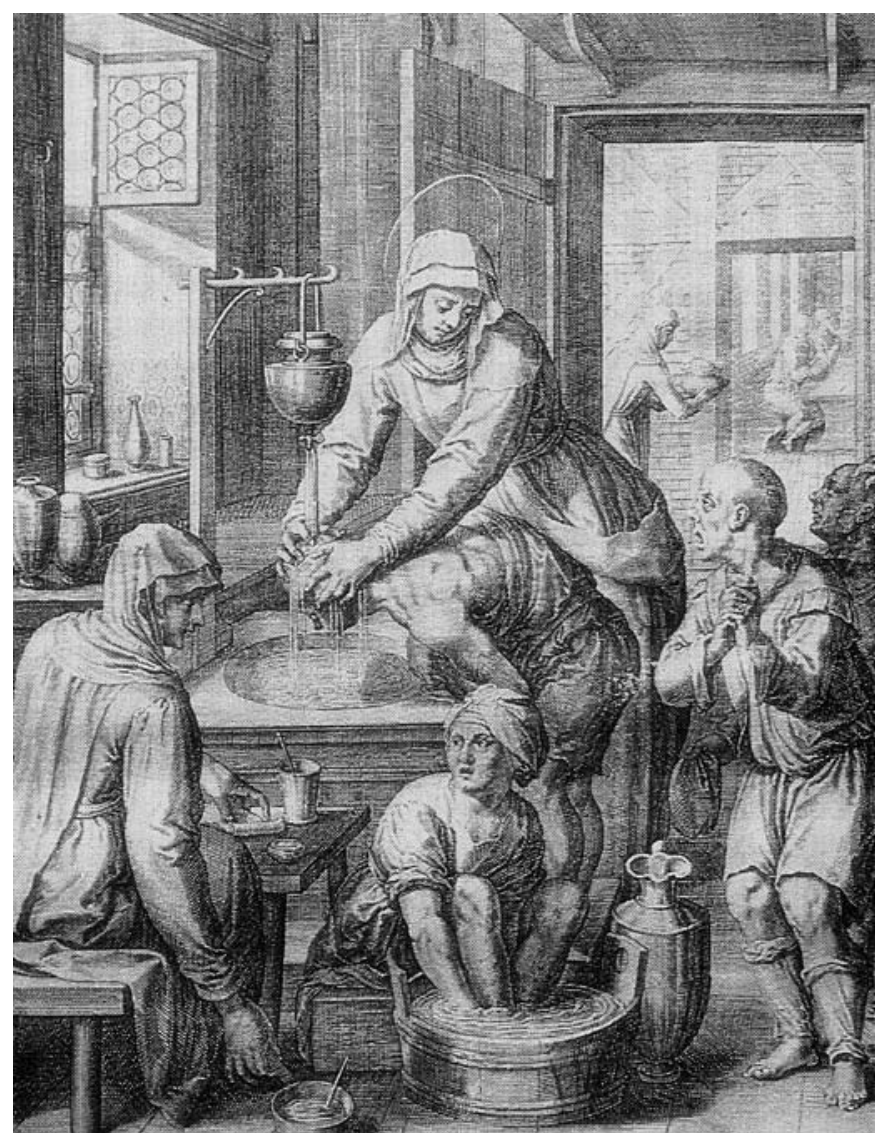

Grabado de Rafael Sadeler (1584-1632) que representa a Santa Erentrudis lavando la cabeza a un enfermo. Fuente: Bavaria Sancta (NAVARRETE PRIETO, 1998)

59 y 60), que aluden a la obligación de curar a los enfermos y dar de comer a los pobres hambrientos acogidos en su hospital.

Dentro del programa iconográfico general de la Iglesia de la Santa Caridad, la obra hace explícita la filosofía de vida de Mañara: es necesario ejercer la caridad de manera personal, aunque se sea noble, como garantía de la promesa de salvación. En sentido figurativo, el hecho de que el lienzo esté situado en una zona baja con respecto al resto de las otras obras, revela la intención de don Miguel de acercar a lo cotidiano las obras de misericordia. La Santa es la única que está en contacto directo con los enfermos lo que demuestra un signo ejemplarizante que pone de manifiesto la santidad de la Reina de Hungría.

\section{Morfología-estilística}

Por su morfología la composición del lienzo se inspira en una estampa de Sadeler ${ }^{6}$, perteneciente al libro Bavaria Sancta ${ }^{7}$, en la que no se representa a Santa Isabel, sino a Santa Erentrudis lavando la cabeza a un enfermo. La elección de esta estampa por parte de Murillo responde a la intención del pintor de ilustrar una escena mucho más realista del acto de caridad representado. Asimismo, para la composición de la escena del fondo, Murillo toma como referencia otra de las estampas de Sadeler, en este caso la referente a Santa Isabel de Hungría del mismo libro.

Murillo representa la escena ubicada en una habitación cerrada, por un lado con un amplio cortinaje que se vislumbra en la oscu-

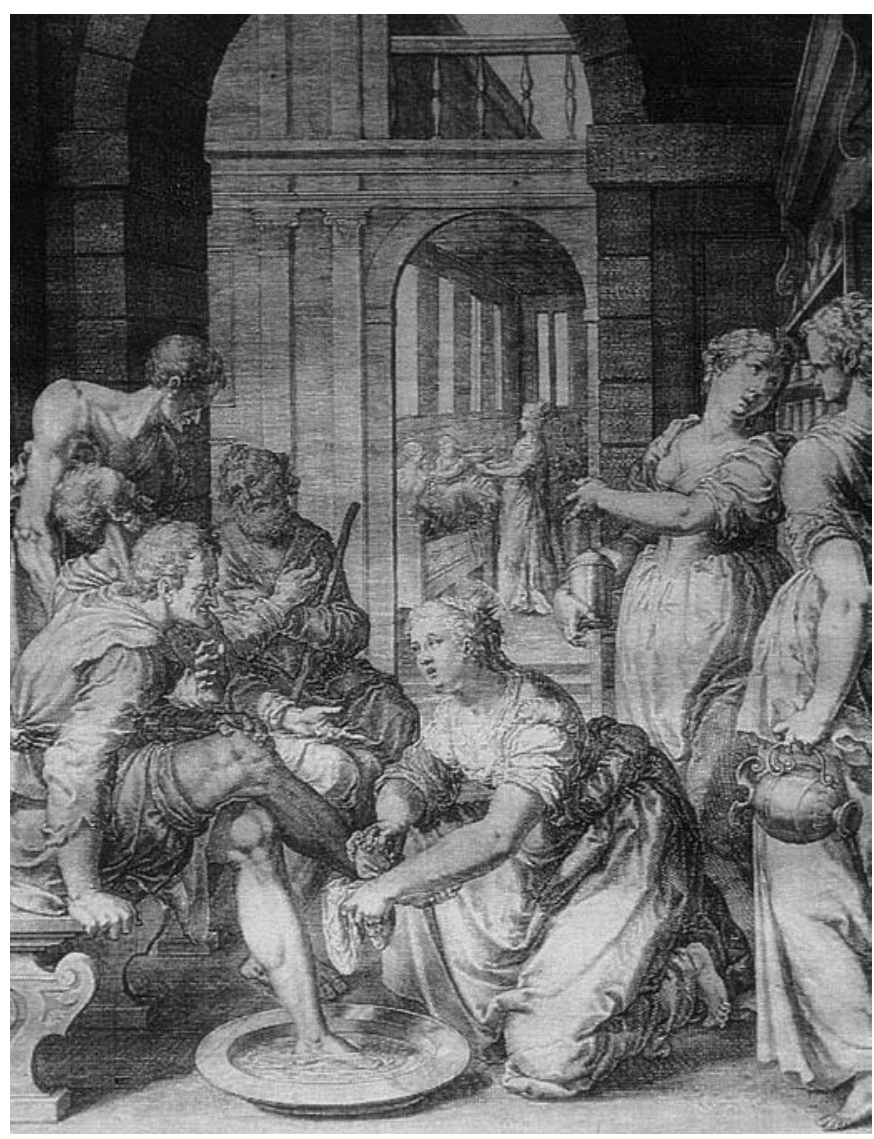

Grabado de Rafael Sadeler (1584-1632) que representa a Santa Isabel de Hungría lavando a un enfermo. Fuente: Bavaria Sancta (NAVARRETE PRIETO, 1998)

ridad y que se contrapone al espacio abierto y lleno de luz de la escena del segundo plano o del fondo.

La Santa aparece rodeada de sus tres damas, más los cinco enfermos y tiñosos a los que cura con sus propias manos. Los enfermos están representados con absoluto realismo, apreciándose incluso sus padecimientos y dolores. Así, el mendigo situado en primer término descubre la llaga de su pierna con gesto de resignación, mientras la anciana del ángulo inferior derecho parece buscar la mirada reconfortante de la santa. En la zona central, al lado de la jofaina o palangana, aparece la figura reclinada de un niño tiñoso, que parece más un bautismo que una curación y donde se refleja la luz como un gran resplandor que le da en la cara. La Santa lava sus Ilagas de la cabeza y cura sus heridas con sus delicadas manos, mientras otro niño a su izquierda espera su cura y por mediación de su mirada directa hace partícipe al espectador de su dolor y picor a través de un simpático gesto que resta crudeza al conjunto. El enfermo que, ayudado por muletas, intenta llegar hasta la galeria para ser atendido, completa el triste grupo de enfermos y tiñosos, a través del cual Murillo consigue realzar, aún más, la figura bondadosa, dulce y bella de Santa Isabel.

Varias doncellas la asisten en su tarea: la primera de ellas, vestida con traje propio del siglo XVII, de color azul verdoso adornado con encajes en el cuello, mangas acuchilladas y adornado con lazo rojo bajo el pecho, porta una bandeja con una especie de jícara con ungüentos más paños y vendas, para curar a los enfermos y sobre su hombro porta una fina toalla con encajes. 


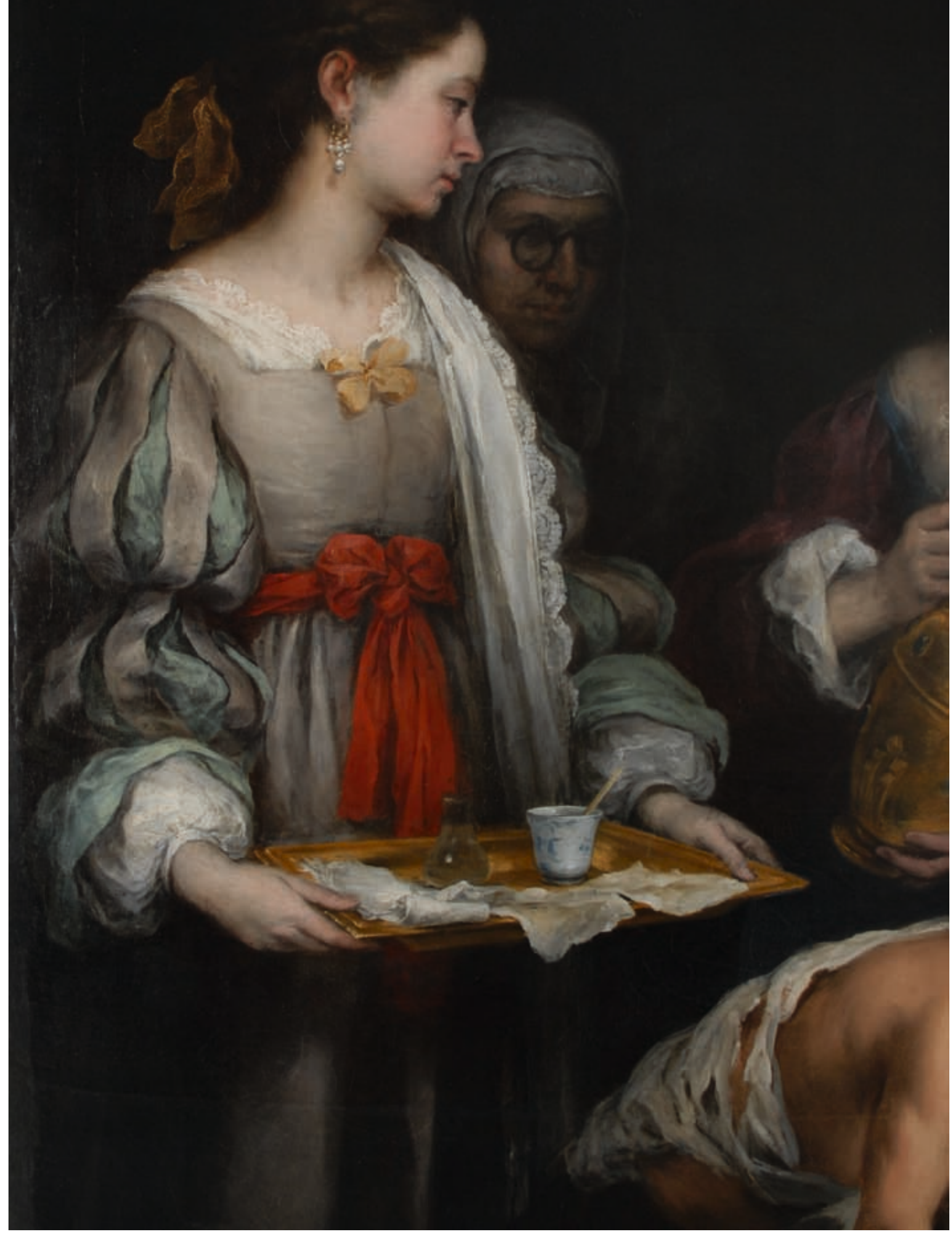


La segunda, vestida de manera similar a la anterior con traje azul, asiste a la Santa, portando una jarra con la que se dispone a enjuagar la cabeza del niño tiñoso.

Cabe señalar que esta jarra, atributo propio de Santa Isabel por el agua para curar, es de estilo manierista, y no barroco, como se deduce por su estilo y sobre todo por los cabujones esmaltados que presenta. La elegancia en el gesto de las dos figuras femeninas, asi como la riqueza de sus ropajes y de los objetos que portan, contrasta con la pobreza de los ropajes de los enfermos y la dureza de sus expresiones, acentuando así el naturalismo de la escena.

Tras ellas se aprecia otra mujer de edad más avanzada, con lentes redondas y con la indumentaria propia del hábito terciario franciscano que observa la escena con gran interés. El hecho de que aparezca tocada con velo, al igual que la santa, hace pensar en su pertenencia a la Orden Tercera Franciscana, de la cual Santa Isabel fue nombrada patrona.

El artista sevillano hace patente en este lienzo de medio punto su interés por las perspectivas arquitectónicas, como ya hiciera en su representación de El sueño del patricio Juan o en la Piscina probática. Esta última obra también pertenece al programa iconográfico diseñado por Mañara para la Iglesia del Hospital de la Santa Caridad. En la actualidad se encuentra expuesta en la National Gallery de Londres.

Murillo divide el escenario en dos zonas yuxtapuestas, una en sombra, en primer plano, donde tiene lugar el tema principal, y otra iluminada, en la lejanía, con las mismas figuras pero más pequeñas enmarcadas por la arquitectura.

La escena se desarrolla entre una cortina recogida y una monumental galería palaciega renacentista, como era habitual en esos momentos, creando en la zona central una composición piramidal que tiene como eje principal a Santa Isabel. Pese a haber sido inspirado en la estampa de Santa Erentrudis, Murillo ha abierto la composición, trasladando al muchacho que se rasca al lado opuesto, para crear un grupo mucho más equilibrado que se completa con el otro niño que esta inclinado para ser curado.

Asimismo hace desaparecer la figura que en primer plano lava los pies del enfermo. De esta manera se crea un gran motivo central Ileno de posibilidades estéticas, que culmina con el rostro iluminado de la Santa y en la actitud de sus manos sobre el tiñoso. Enriquecen la escena las figuras del enfermo que se quita la venda de su pierna y la realista figura de la anciana de la derecha. Por otra parte, el acusado cambio de escenario de la agobiada cámara nórdica de la estampa de Sadeler en la que se representa a Santa Isabel, a la amplia estancia renacentista contribuye aún más a una mayor claridad compositiva.

Murillo concibe la obra en base al color y no en base a formas precisas ceñidas por el dibujo. Para ello emplea una suave paleta de colores a través de valientes y desenfadadas pinceladas. La luz dorada, que ilumina la estancia desde el ángulo superior derecho, baña todos los personajes creando una atractiva sensación atmosférica, que diluye los contornos, pero no omite ninguno de los detalles, como las calidades de las telas o los reflejos de luz en porcelanas-vidriadas y metales. Este matizado empleo de la luz enriquece la composición, destacando en el grupo principal el delicado cromatismo del rostro y manos de la santa, sobre un fondo en parte en sombra y en parte iluminado en la lejanía.

En el segundo plano, se representa un escenario con un espectacular pórtico donde se contempla una escena secundaria en la que se representa a Santa Isabel dando de comer a los pobres. Esta estancia se encuentra coronada por una balaustrada semejante a la que Sadeler emplea en la estampa de Santa Isabel. A través de este grupo queda ilustrada la segunda parte del ejercicio caritativo entre los hermanos de la Caridad, de los que Murillo formó parte desde 1665.

Murillo, a pesar de pertenecer a una época en la que el barroco mueve violentamente actitudes y composiciones, conserva siempre una gran serenidad y gusto por la belleza, como la que emana del lienzo de Santa Isabel, claro ejemplo de la maestría con la que el pintor sevillano da forma plástica al sentimiento religioso y caritativo, a partir de su acusada sensibilidad artística.

\section{CONSERVACIÓN-RESTAURACIÓN}

\section{Introducción al estudio material de las restauraciones}

La actuación de conservación-restauración que se ha llevado a cabo sobre esta pintura ha estado motivada por los deterioros ocasionados por la degradación de los materiales utilizados en las distintas intervenciones realizadas sobre la misma.

La obra Santa Isabel de Hungría curando a los tiñosos ha tenido una vida azarosa. Las distintas etapas vividas por la pintura incluyen largos viajes, cambios de formato y diversos lugares y condiciones de almacenamiento y exposición.

Todas las restauraciones que ha sufrido están directamente relacionadas con los traslados llevados a cabo durante su larga historia. El estudio de los distintos materiales encontrados durante el proceso de restauración ha permitido establecer el número de intervenciones realizadas.

Cuando la obra sufrió el expolio de los franceses en 1811 habian transcurrido más de 130 años desde su ejecución, periodo en el que ya habría sido sometida a restauraciones, como podremos ver en el apartado que dedicamos al tratamiento.

Se tenía conocimiento de la existencia de una reconstrucción pictórica muy burda, pero se desconocía el alcance de esa interven- 
ción. El estudio radiográfico ha revelado las condiciones reales en las que esta zona se encuentra.

La apariencia, a simple vista, del área afectada mostraba una delimitación con la pintura original recta y descendiente de derecha a izquierda. Abarca esta zona gran parte del suelo sobre el que se apoyan los bajos de la falda y pies de la anciana sentada a la derecha, y los pies del mendigo situado a la izquierda.

El bien debió sufrir un accidente en el largo trayecto hacia Francia, quedando afectada por numerosos desprendimientos de pintura y preparación, la zona triangular delimitada por esa línea recta.

Cuando la obra llega a Francia, para formar parte de la colección del Museo de Napoleón es modificado su formato original, y fue necesario reentelarla. Es entonces cuando se añaden las enjutas doradas y se realiza la reconstrucción pictórica de la zona baja. Los análisis de los materiales constitutivos y las estratigrafías -de las muestras tomadas en estos espacios- indican en los resultados los mismos materiales: una gruesa capa de preparación elaborada con carbonato cálcico y una sola capa de pintura con una granulometria muy homogénea (véase estratigrafía no 1, p. 30).

La reconstrucción pictórica realizada entonces fue, además de muy tosca, torpe en su ejecución, y presentaba restauraciones posteriores superpuestas que aún la hacian más antiestética.

Toda la pintura está ejecutada sobre una preparación dada con espátula dentada, con la intención de que las muescas producidas imitaran a las pinceladas. Este recurso no hizo sino intensificar el aspecto de falso histórico.

Contrariamente a lo que en un principio se pensaba con respecto al lienzo, no se realizó un corte lineal para sanear ese fragmento sino que, según se comprobó estudiando los bordes, el tejido original permanece integro (incluso mantiene el orillo del borde inferior).

Esta restauración motivó la reflexión de Ceán Bermúdez recogida por Diego Angulo: "Le transportaron a París, donde con deseo de limpiarla le desfloraron los tiernos velos y últimos toques que le diera su autor al concluirle" (ANGULO í̃̃GUEZ, 1981).

Se ha podido constatar, al finalizar la fase de limpieza, que esas últimas pinceladas -realizadas de forma más delicada-, ya fueron afectadas con anterioridad al expolio por una restauración más antigua. Efectivamente los desgastes atañen a las pinceladas finales que perfilaban algunos rasgos de los rostros, como las cejas o los tonos rosados de los labios que actualmente aparecen insinuados.

Hay que puntualizar que en este caso no se puede hablar de veladuras, ya que no es una técnica habitual del barroco naturalista, son ligeros trazos de acentuación localizados en determinadas zonas de la pintura.

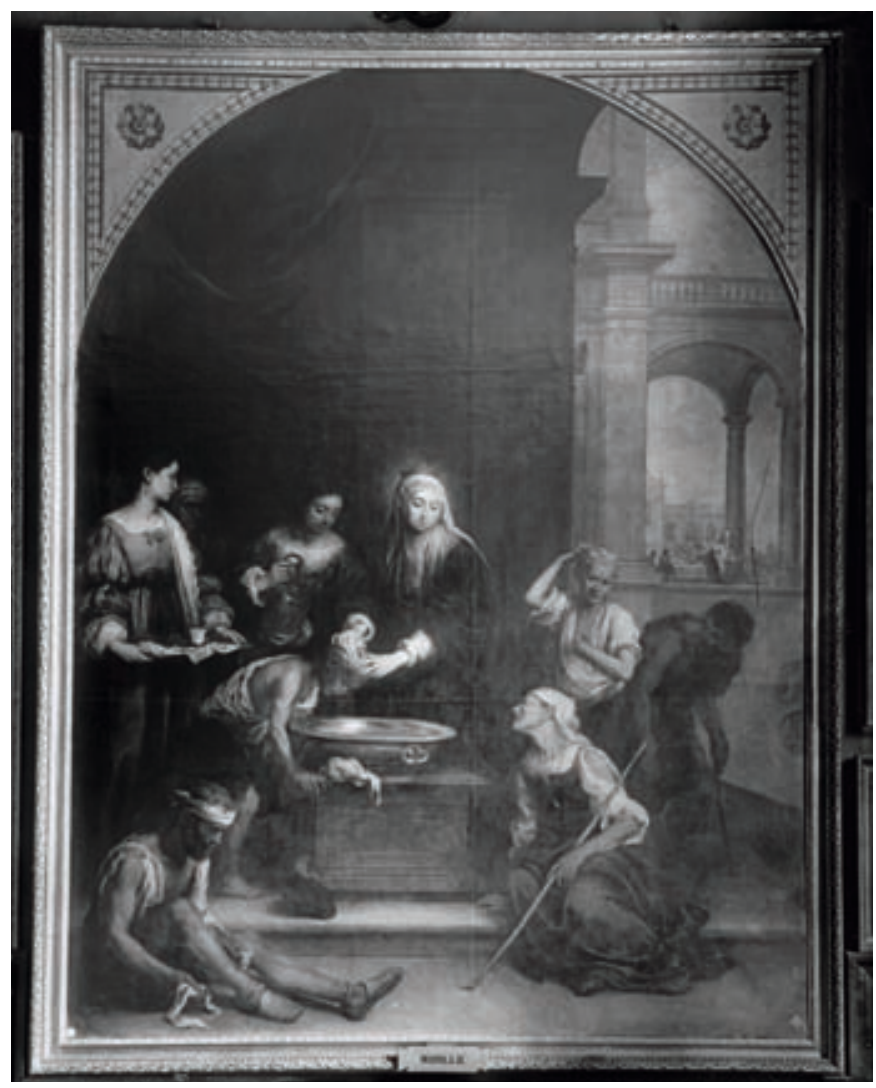

Fotografía general. Fuente: Archivo Moreno. IPCE. Ministerio de Cultura

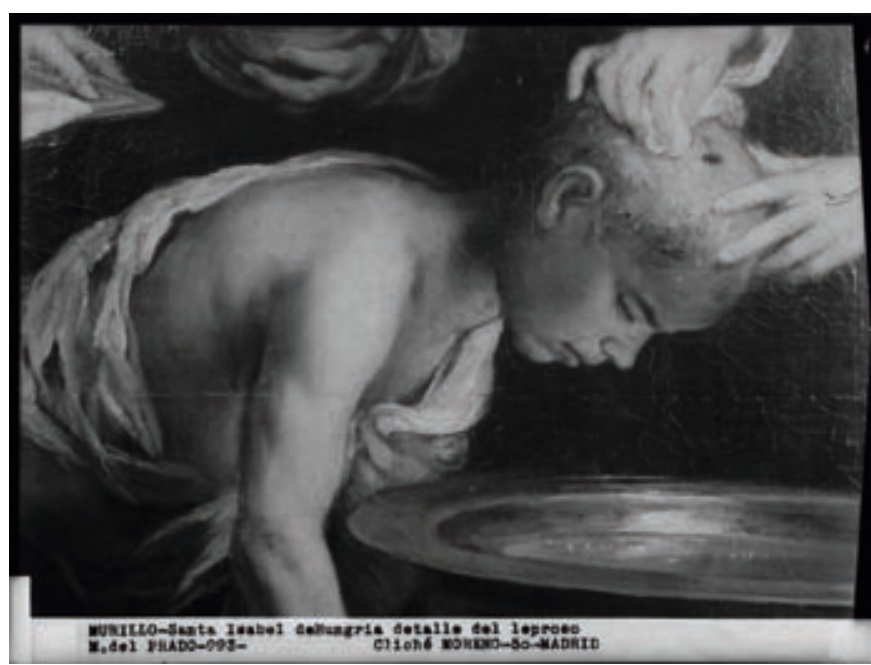

Fotografía de detalle. Fuente: Archivo Moreno. IPCE. Ministerio de Cultura

En las fotografías realizadas al cuadro entre los años 1893-1901, pertenecientes a los fondos del Archivo Moreno, la obra se muestra con el formato rectangular tal y como fue devuelta a España. De esta forma permaneció durante su almacenamiento en la Real Academia de San Fernando y posteriormente expuesta en el Museo del Prado.

En la imagen general de la obra se pueden apreciar las deformaciones y desgastes que presentaba. Otros datos interesantes son una etiqueta redonda adherida a la pintura, cercana al ángulo inferior izquierdo, cuyos números no son legibles; y lo que parece un pequeño papel cuadrado, adherido -sobre la pintura falsa- en el ángulo inferior derecho. En el listón inferior del marco se ve incorporada la 
cartela característica del Museo del Prado. Esta imagen general es la que se incluye en el estudio sobre Murillo de Diego Angulo İñiguez (ANGULO ÍÑIGUEZ, 1981: Tomo III, Lámina 285).

La foto de detalle muestra de forma más cercana los desgastes que afectaban a los bordes de los grandes craquelados. Esta fotografía lleva incorporada anotaciones relativas a la obra, entre las que figura "M. del Prado-993-", posible número de inventario.

Por los materiales hallados en el curso de la restauración se podría afirmar que la obra fue de nuevo tratada antes de exponerla en el Museo del Prado, debido al mal estado de conservación que presentaban los materiales usados en Francia y por las malas condiciones de almacenamiento y abandono en que estuvo en la Real Academia de San Fernando de Madrid (GAYA NUÑO, 1978). Cuando vuelve a Sevilla para ser colocada en su altar se realizan sobre la obra algunos trabajos menores de carácter parcial.

\section{DESCRIPCIÓN DE ELEMENTOS CONSTITUTIVOS-ESTADO DE CONSERVACIÓN}

\section{El bastidor}

La obra presenta actualmente un bastidor del siglo XX, concretamente del año 1939 -como indica una anotación a lápiz escrita en el reverso, situada en el ángulo inferior derecho-. En esa fecha, a la pintura se le devuelve su formato original, montándola sobre un bastidor de medio punto. Por el reverso del arco superior -adheridos al tejido del reentelado- se conservan restos de la preparación y de la policromía dorada con que fueron realizadas las enjutas del arco.

El bastidor actual está constituido por 10 piezas de madera de pino. Los ensambles son machihembrados con cajas para cuñas de haya en los listones perimetrales. Consta de dos travesaños verticales y dos horizontales formando crucetas. Los travesaños están ensamblados a los listones perimetrales mediante horquillas, con la lengüeta interior en caja pasante y la externa, con los bordes

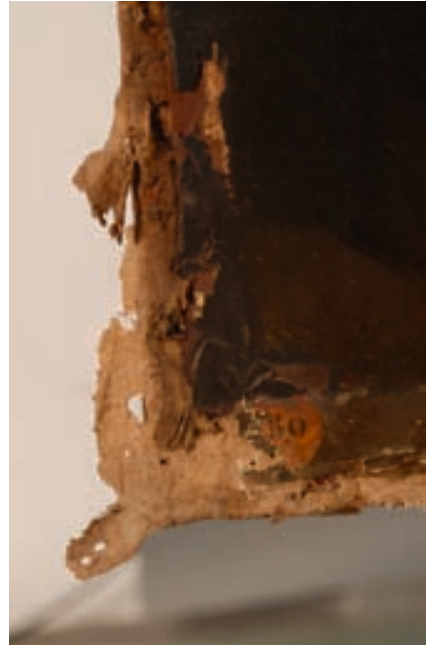

Deterioros de los bordes del lienzo. Foto: Amalia Cansino Cansino

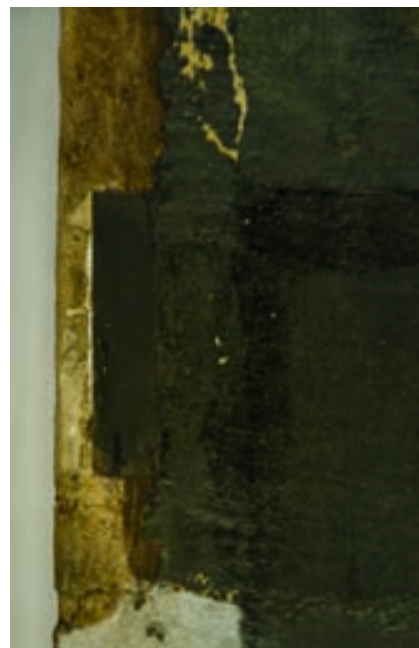

Proceso de limpieza del borde lateral. Foto: Eugenio Fernández Ruiz, IAPH redondeados. La posición y grueso de la horquilla interna distancia el lienzo de la estructura de madera $5 \mathrm{~mm}$. Todos los listones presentan las aristas internas rebajadas.

Aunque este bastidor corresponde a una intervención relativamente reciente, tiene una ligera modificación en las medidas. El listón inferior es más estrecho que el resto debido a que fue recortado $2 \mathrm{~cm}$. Probablemente, en el momento de colocar el cuadro en su capilla original, no entraba con facilidad y recortaron por abajo.

La obra estuvo fuera de Sevilla 128 años. Se sabe que durante este largo periodo de tiempo la capilla albergó otra obra, cuya identidad y caracteristicas desconocemos. Para su ubicación ampliaron ligeramente el hueco existente, por lo que cuando volvieron a reubicar la obra de Murillo tuvieron que montar el lienzo en un bastidor algo mayor que el original.

Debido a esta ampliación en todo el perimetro de la pintura, exceptuando el borde inferior, se observa un espacio sin pintura de unos $3 \mathrm{~cm}$ que corresponde a la vuelta de la tela original sobre el primer bastidor utilizado por Murillo. También se conservan los agujeros que corresponden a las primitivas tachuelas que estuvieron colocadas a intervalos de unos $2,5 \mathrm{~cm}$.

\section{Los lienzos}

El lienzo original es una tela gruesa de ligamento simple (tafetán) elaborada con lino de segunda calidad. Está compuesto por tres piezas horizontales, por tanto, consta de dos costuras. Los dos paños inferiores miden $110 \mathrm{~cm}$, mientras que el superior -hasta la clave del arco- mide $105 \mathrm{~cm}$. La anchura máxima del tejido corresponde a una vara portuguesa, medida habitual de los lienzos utilizados por Murillo en numerosas obras.

El paño central y el inferior conservan los dos orillos, manteniendo la correcta fortaleza del soporte. Las costuras están realizadas, al borde de los orillos, con "punto por encima".

El tejido usado como reentelado está formado también por tres piezas de lino situadas verticalmente, en sentido contrario al soporte original. Los tres paños están unidos por dos costuras hechas a mano de forma tan perfecta que las puntadas son prácticamente iguales. También es una señal de perfección de este trabajo que los orillos presenten cortes inclinados a intervalos de unos $10 \mathrm{~cm}$, dejando sin cortar unos $3 \mathrm{~mm}$ antes de llegar a la costura. Estos cortes se realizaron, para que la tensión de la tela, reforzada en esta zona por la vuelta de los hilos de trama, no provocara tensiones que pudieran alterar el tejido original. Sobre el lienzo central, situado en la zona superior, figura el " $N^{\circ} 43$ " realizado con tinta roja.

Los bordes de ambos soportes se encontraban en muy mal estado de conservación, con roturas y desgarros en todo el perimetro, a lo que se añadian restos de cola, de papeles adheridos y deterioros provocados por la oxidación de los clavos. Estos daños se produjeron 
por los diversos montajes y desmontajes que la obra fue sufriendo a lo largo de su historia, por los traslados arrastrando la obra sobre el listón inferior, por almacenamientos incorrectos y por el inevitable envejecimiento natural de los materiales.

Los deterioros enumerados afectaban en mayor medida al borde inferior $y$, especialmente, a la tela del reentelado que mostraba numerosos desgarros y faltas. Los tejidos de esta zona presentaban mala adhesión entre ellos, con una separación en algunos tramos de hasta $7 \mathrm{~cm}$.

También estaba afectado el soporte por una gran deformación que coincidia exactamente con la reconstrucción del siglo XIX. Esta deformación produjo un abombamiento de los lienzos debido a la tensión creada por la gran acumulación de materiales existentes en esta zona.

\section{La pintura}

En el estudio previo, realizado in situ a la pintura antes de iniciar el proyecto, no se apreciaron grandes destrozos. Al no existir fragmentos con peligro de desprendimientos, no fue necesario realizar un empapelado de protección antes de proceder al traslado al $\mathrm{IAPH}$, y de esta forma se evitó aplicar una humedad innecesaria.

La pintura original presentaba un estado de conservación estable. Murillo unía a su maestría en la ejecución pictórica un gran cuidado a la hora de preparar los lienzos, las preparaciones de base y los colores. El uso del aceite de lino como aglutinante de la pintura y de las preparaciones hace que los distintos estratos queden muy cohesionados; por ello, a pesar de los malos tratos recibidos, han podido llegar sus obras a nuestros dias en unas aceptables condiciones de conservación.

La alteración de mayor importancia era de carácter estético, ya que la degradación de los materiales añadidos a la pintura, cubiertos a su vez por los barnices oxidados, habían impedido durante años la visión real de la pintura. En el estudio realizado con luz ultravioleta, las capas de barnices se mostraban tan densas que los numerosos repintes existentes bajo ellas se percibian velados.

La reconstrucción pictórica de la zona baja apenas mostraba signos de fluorescencias, debido a su antigüedad. En cambio, sí se apreciaron con claridad numerosas manchas oscuras correspondientes a las restauraciones más recientes, realizadas tanto sobre la pintura original como sobre la reconstrucción deI XIX. Especialmente oscuras se mostraban las últimas intervenciones realizadas sobre el barniz, con la obra montada en la capilla, localizadas en todo el perímetro de la pintura.

Algunos colores originales muestran degradación natural debido al uso de determinados pigmentos. El más importante es el oscurecimiento de los azules utilizados en el vestido y en el lazo del cabello de la dama de la jarra. Esta degradación es debido al uso de azul de

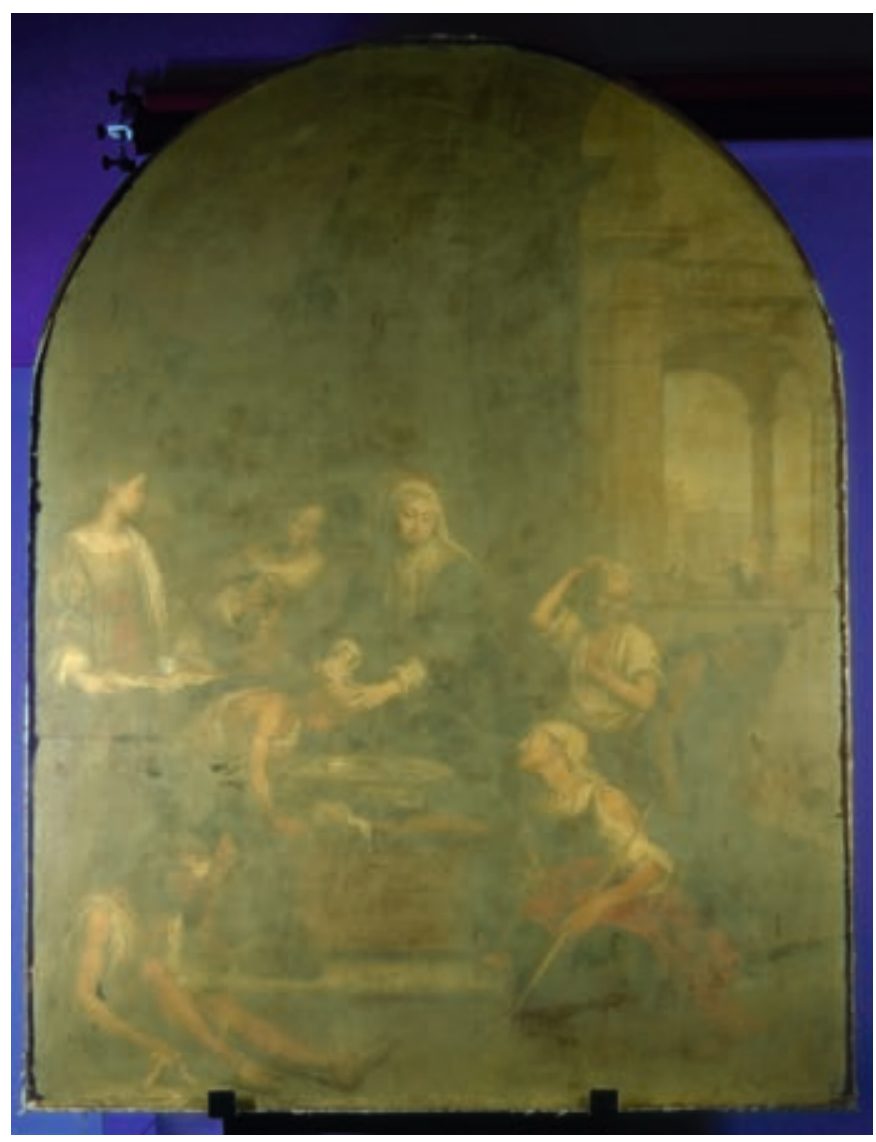

Fotografía general con luz ultravioleta. Foto: Eugenio Fernández Ruiz, IAPH

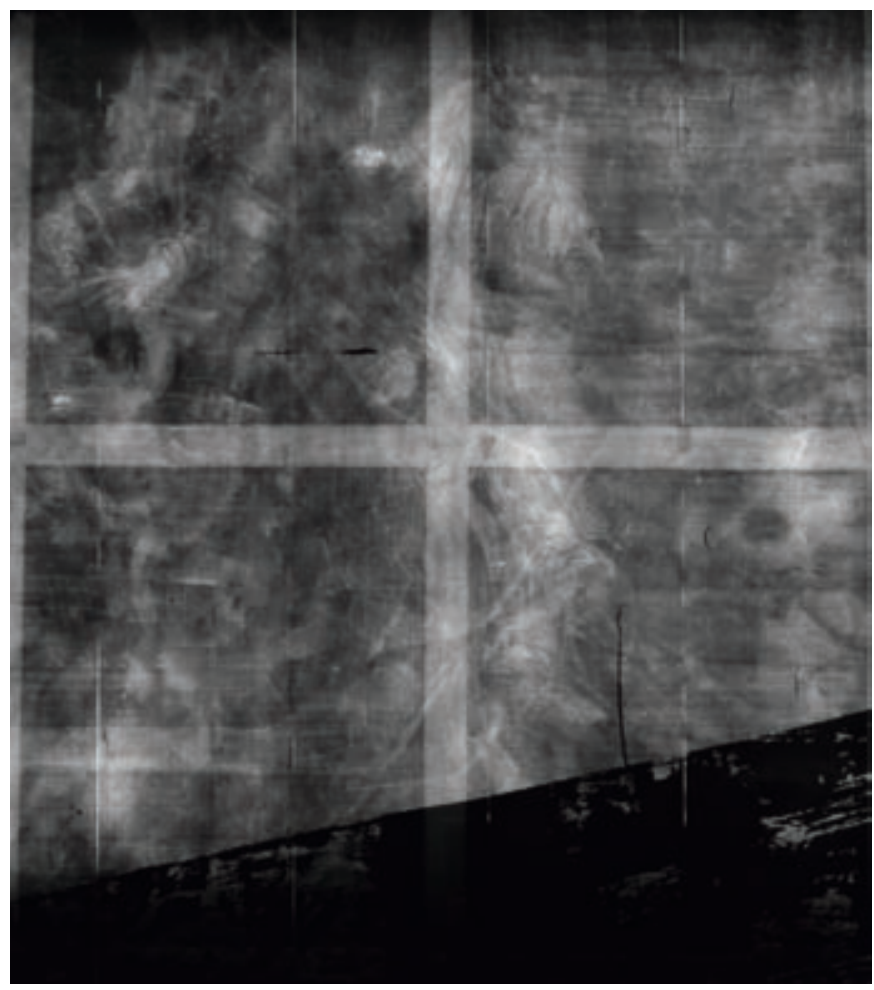

Imagen radiográfica que refleja la importante falta de pintura en la zona baja. Foto: Eugenio Fernández Ruiz, IAPH 
esmalte para las zonas de sombra. Para las zonas de luz Murillo utiliza, sobre la capa de esmalte, azurita (véase estratigrafía no 2 , p. 30 ).

\section{ESTUDIO RADIOGRÁFICO}

La imagen radiográfica de la pintura da una primera sensación de confusión debido a que tanto las zonas claras de la pintura como las capas de preparación e imprimación contienen abundante blanco de plomo. La superposición de las distintas capas impide la visión clara de los rasgos pictóricos y del perfecto dibujo que los definen.

Aún así, las formas se perciben fácilmente por el contraste radiográfico que ofrecen las zonas claras de la pintura, realizadas con más proporción de albayalde. Los encajes que adornan los ropajes de las dos jóvenes damas, el rostrillo que rodea la cabeza de la Santa Isabel y, en general, todos las zonas claras son claramente visibles, lo que ayuda a localizar fácilmente las figuras.

En las radiografías también se aprecian con claridad la armadura del tejido y las puntadas de unión de las costuras, debido a la impregnación de este por la preparación realizada con blanco de plomo.

Esta preparación se untó utilizando una espátula de unos $5 \mathrm{~cm}$ de anchura. En toda la superficie de la pintura se pueden ver las señales de este instrumento siguiendo siempre la dirección de la acción de la mano al untar la pasta.

También se aprecia con claridad el espacio de lienzo libre de los bordes. Un gran espacio sin contraste entre las tachuelas y en borde de la pintura. En cuanto a los deterioros se han observado los desgarros de los bordes y pequeñas faltas de pintura existentes a lo largo de las costuras. Una gran falta de pintura afecta a la figura de la joven dama con la jarra. Es una grieta en sentido diagonal que comienza en el hombro, le cruza el rostro y llega hasta el fondo.

El hallazgo más sorprendente de este estudio se localizó en la zona baja del lienzo, con la constatación de la delimitación lineal percibida en el estudio visual. Bajo esta línea divisoria hay un gran vacío de pintura original. De la obra de Murillo sólo quedan pequeños retazos distribuidos en los laterales del gran espacio deteriorado. La zona central donde se encontrarian los pies y los ropajes de la mendiga anciana están totalmente perdidos, lo que justificaría la reconstrucción pictórica realizada en París. La visión de este gran espacio negro ha sido posible porque los materiales utilizados para la reconstrucción no dan ningún contraste radiográfico.

\section{TRATAMIENTO REALIZADO}

En primer lugar se actuó sobre el bastidor, que, como se ha explicado, presentaba buen estado de conservación. La actuación sólo consistió en la limpieza de los depósitos superficiales y de las acumulaciones de suciedad introducida entre el listón inferior y el soporte de lienzo.

La primera parte del trabajo realizado para la consolidación del soporte se comenzó con el cuadro colocado en posición horizontal y con el anverso hacia arriba. Una vez protegida la superficie pictórica de la zona baja con papel Japón, en un fragmento de unos $25 \mathrm{~cm}$, se procedió a retirar solamente los clavos del listón inferior del bastidor, así como unos $25 \mathrm{~cm}$ hacia arriba de los listones laterales. Este desclavado parcial se realizó a fin de liberar el soporte y trabajar en los bordes rasgados sin dañar la pintura.

Paralela al listón inferior del bastidor se colocó una madera de la misma altura y longitud para apoyar el soporte y poder actuar sobre los lienzos en una superficie plana, continua. Las grandes deformaciones se eliminaron mediante humedad y peso. Los desgarros, previamente enderezados, se colocaron en su sitio intentando llevar cada hilo a su posición original. Una vez unificados todos los fragmentos, las faltas de soporte de ambos lienzos -el original y el añadido- se reconstruyeron colocando hilos de lino siguiendo la dirección del deterioro. Unas veces en el sentido de la trama y otros en el de la urdimbre. Después del tratamiento de ambos lienzos se procedió a su adhesión utilizando el mismo adhesivo del reentelado, gacha tradicional de cola animal y harina. De esta forma, sin introducir nuevos elementos, se ha mantenido la continuidad de los estratos ya existentes.

Posteriormente se continuó el tratamiento colocando la obra con el anverso hacia abajo para trabajar en el reverso del lienzo sobre la zona anteriormente tratada. Se enteló el borde inferior con una banda de tejido de lino cuyo borde se aligeró mediante flecos desfibrados. En esta ocasión el adhesivo utilizado fue Beva film ${ }^{\circledR}$, pues se trabajó sobre la tela del reentelado. Era el material más adecuado, ya que el uso de un medio acuoso hubiera despegado todo el trabajo anterior.

Para adherir la banda de lino se separó el bastidor del lienzo lo mínimo posible. Con la ayuda de cuñas se levantó el bastidor el espacio suficiente para introducir la punta de la espátula caliente utilizada para la adhesión de ambas telas. Los tejidos debilitados del borde quedaron reforzados y el tejido sobrante facilitó el tensado posterior del lienzo, eliminando de esta forma la deformación. Con la obra en esta posición se procedió a la fijación de los restos de pintura dorada que se conservaban sobre la tela del reentelado a lo largo de todo el medio punto, con la intención de conservar restos importantes de la historia material de la pintura.

\section{Primera fase de limpieza}

El tratamiento de limpieza realizado a esta pintura ha sido, con diferencia, la fase de trabajo más compleja, la que ha presentado mayor dificultad y la que ha requerido el mayor esfuerzo y tiem- 

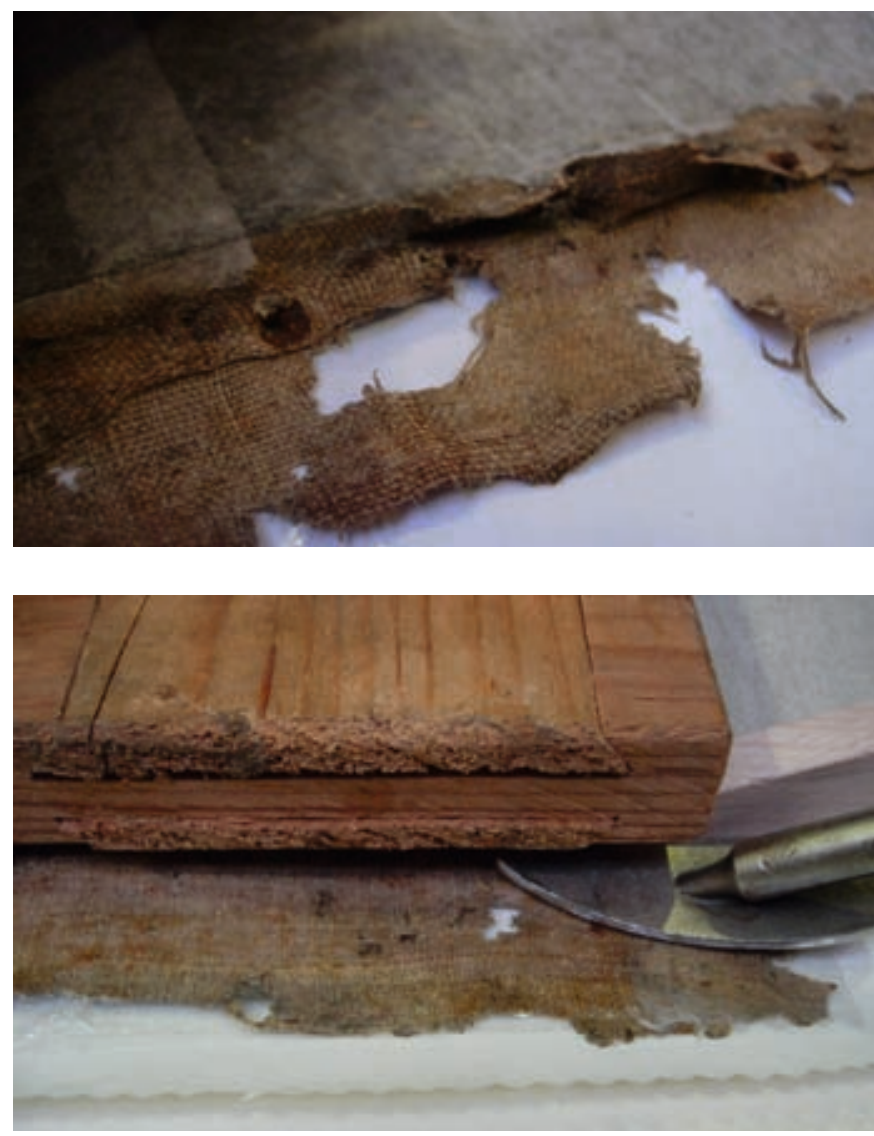

Estado inicial y tratamiento de los bordes. Fotos: Amalia Cansino Cansino

po del proyecto. Una vez conocida la materialidad de la obra a través de los estudios y análisis previos, se decidió realizar una intervención integral de limpieza a fin de devolver a la obra su color original.

El orden de eliminación de las diferentes capas siempre es inverso al orden en que fueron depositadas sobre la superficie de la pintura, por tanto, el primer elemento removido fue un estuco marrón que cubria los bordes de la pintura en todo su perímetro, menos en el borde inferior. Esta intervención, perfectamente visible en el estudio con luz ultravioleta, correspondía al momento en que la obra se volvió a colocar en su capilla de Sevilla.

Para ocultar los $3 \mathrm{~cm}$ de tejido original visible, se dio el estuco con la obra colocada en la capilla. La pasta dejó un borde exterior perfectamente recto porque se apoyó en la moldura. Este material, de composición yesosa, que fue fácilmente eliminado con agua templada, había teñido de color marrón oscuro el lienzo original, por lo que tuvo que ser limpiado minuciosamente para no contaminar los materiales de trabajos posteriores. Debajo de esta pasta oscura aparecieron indicios de otra restauración anterior, concretamente unos papeles de unos $2 \mathrm{~cm}$ de anchura situados en todo el borde de la pintura original, excepto en el medio punto. Esto significaba que los papeles se colocaron cuando la obra tenía formato rectangular. Es costumbre en algunos talleres la colocación de papeles como protección de los bordes para evitar roces con el marco. En este caso eran fragmentos con escritura en latín. Bajo ellos se hallaron restos de estucos blancos compuestos por carbonato cálcico.
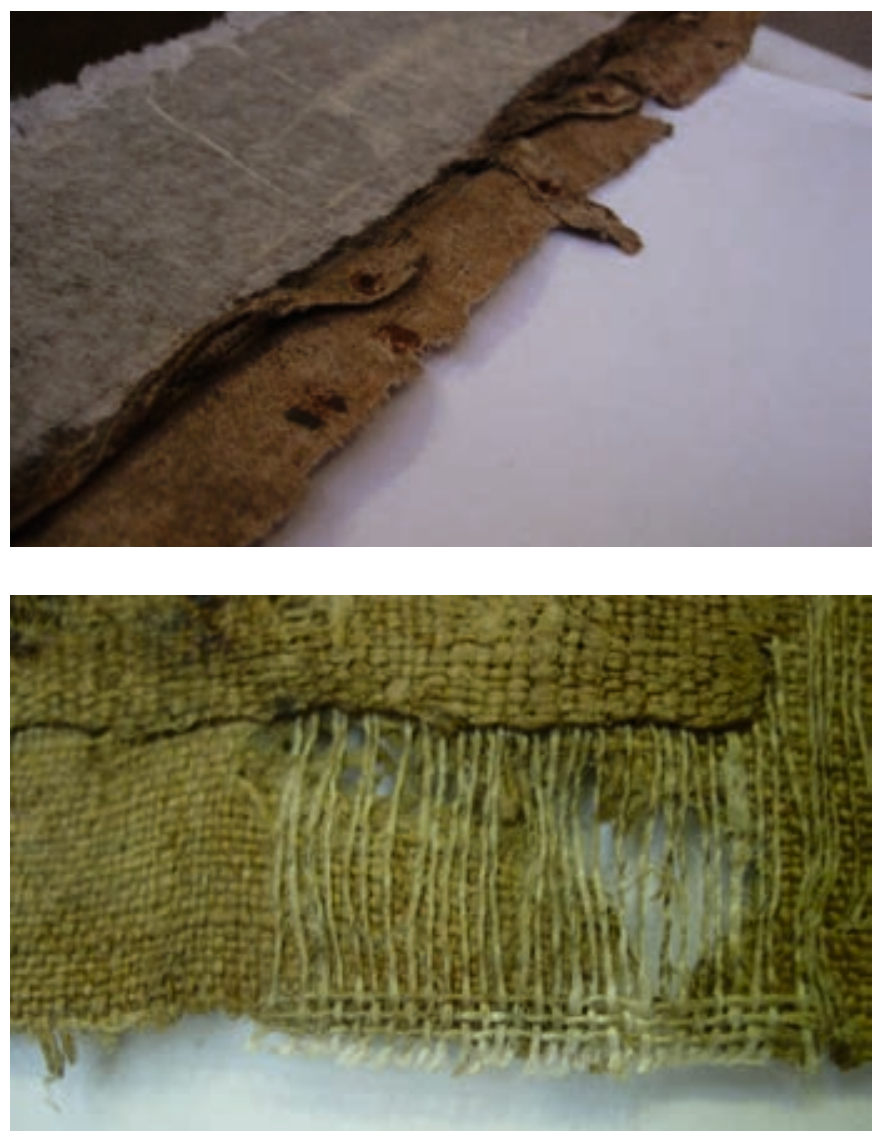

La gruesa capa de barnices amarillentos que cubría toda la superficie de la pintura estaba compuesta por almáciga. Esta resina triterpénica se vuelve totalmente amarillenta con el tiempo. En algunos lugares estaba teñida con pigmentos para camuflar desgastes y zonas complicadas, como la unión lineal situada en la mitad inferior. Esta capa color caramelo perturbaba totalmente la apreciación de los colores originales, volviendo los azules, verdes, y los plateados, dorados, como en el caso de la jofaina.

Una vez eliminada, se apreciaron con más claridad los delicados detalles de la ejecución pictórica que quedaban ocultos como, por ejemplo, los finos trazos de la piel de visón con que está forrado en manto de Santa Isabel. También se hicieron visibles los colores reales de los ricos ropajes de la dama de la bandeja, así como la figura de la monja situada detrás de esta figura, que apenas resultaba perceptible.

Se hallaron numerosas reintegraciones cromáticas realizados al óleo, ya oscurecidas. La más importante estaba localizada sobre la falta de pintura que afecta a la joven dama de la jarra. Otras intervenciones puntuales se localizaban en las costuras. Los estucos utilizados para rellenar estas faltas tienen la misma composición que la preparación de las enjutas y de la zona reconstruida. Han sido conservados en esta intervención, porque se encontraban en buen estado de conservación.

En la pintura reconstruida fue más dificultoso el trabajo de limpieza pues la pintura, compuesta por pigmentos aglutinados con un aceite secante de gran acción, había retraido deslizándose sobre la preparación. Este deterioro era muy evidente en la falda azul de la anciana, 


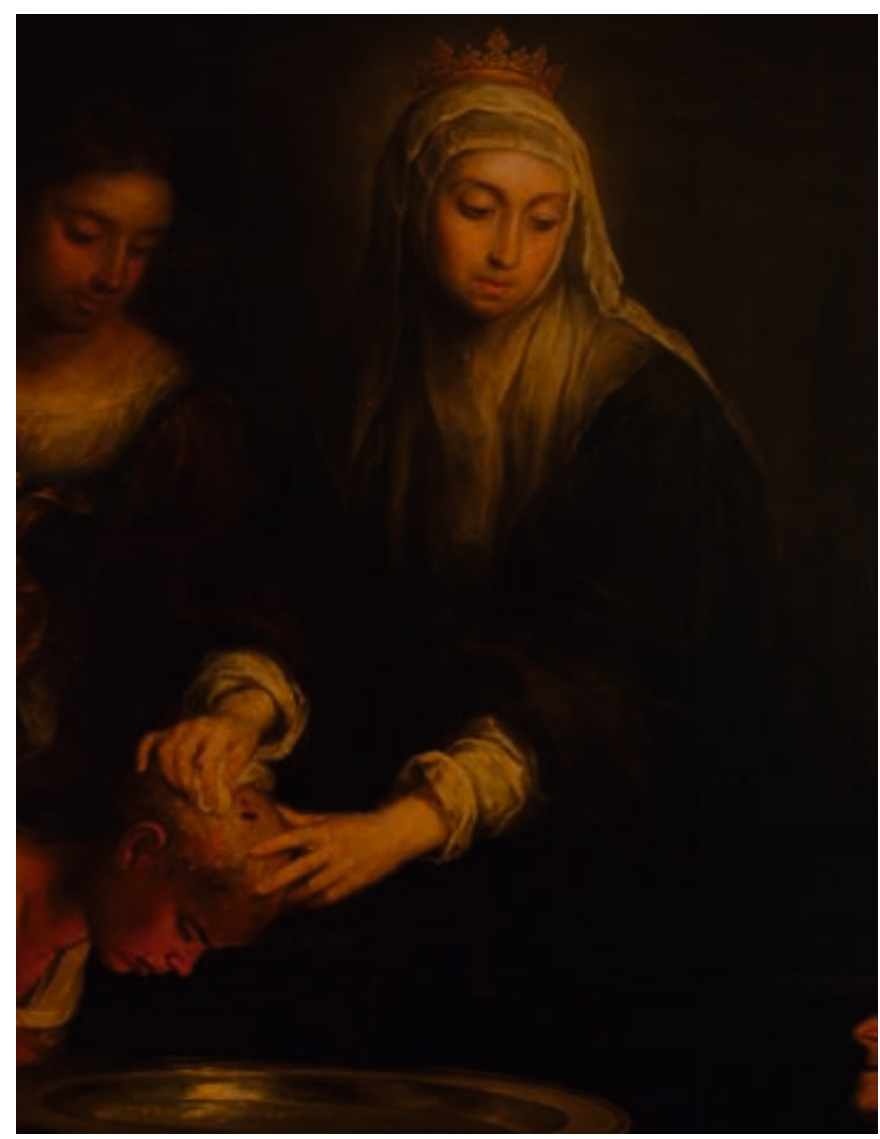

Estado inicial de Santa Isabel. Foto: Eugenio Fernández Ruiz, IAPH

realizada con azul de Prusia, que mostraba una retícula blanca en toda la zona. Esta pintura azul continuaba hacia arriba y oscurecía, repintándolo, el azul original de Murillo realizado con azurita. También el manto rojo estaba afectado por el mismo tipo de repinte (véase estratigrafía no 3, p. 30).

Las alteraciones habían sido a su vez "restauradas", lo que nos sitúa en la actuación realizada para exponerla en el Museo del Prado. Este trabajo era aún más tosco que el anterior pues se había realizado con betún de Judea. Este material daba un brillo excesivo a partes de la zona inferior, afectando, principalmente, a las sombras de la unión de los ropajes con el suelo y reconstruía las partes degradadas de los pies y de las alpargatas del mendigo sentado. De la etiqueta redonda que permanecia entera en la foto del Archivo Moreno, actualmente sólo existen los dos últimos dígitos (80). La etiqueta se ha restaurado y de esta forma se ha conservado para posibles estudios futuros. En el ángulo inferior derecho de la pintura, situada sobre la reconstrucción y realizada con óleo de color azul figura la anotación "T 2395", probablemente relacionada con el Convento de la Trinidad.

Para eliminar el grueso de materiales que abombaba el lienzo se eliminaron todos aquellos añadidos dejando solo la pintura inicial. Entonces empezaron a apreciarse por transparencia los retazos de pintura original que habian sido cubiertos por los repintes. Se realizaron calcos de toda la zona que fueron superpuestos a la misma zona del cuadro. De esta forma se localizaron y recuperaron pequeños fragmentos de pintura original, que sirvieron de referencia para el posterior trabajo de reintegración cromática.

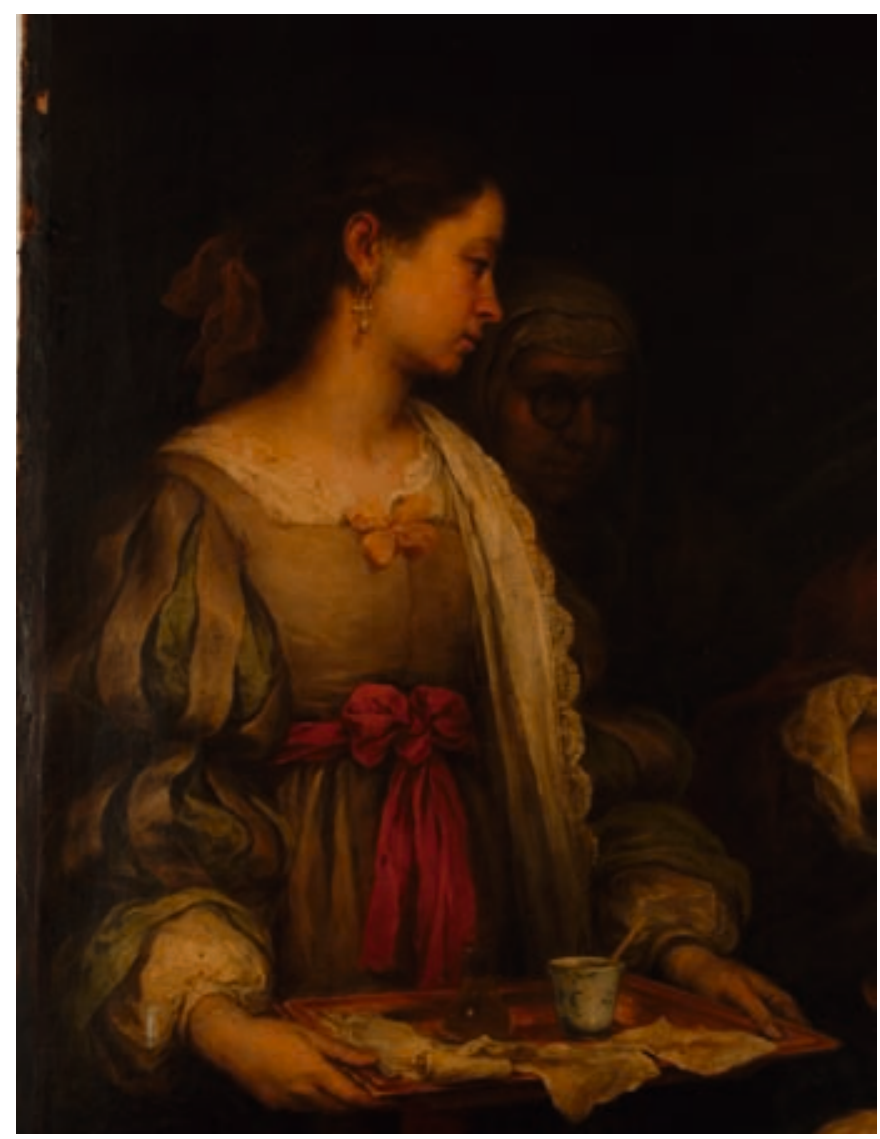

Estado inicial de dama con bandeja. Foto: Eugenio Fernández Ruiz, IAPH

\section{Segunda fase de limpieza}

Una vez eliminados todos estos elementos, la pintura original no mostraba la calidad exquisita del pintor, seguía presentando un aspecto plano y sin profundidad. Una pequeña cata de limpieza realizada en el celaje de la segunda escena reveló la existencia de una capa de barniz más antigua, que solo afectaba a la pintura original y que no había sido eliminada en las restauraciones anteriores.

La eliminación de esta capa de tono grisáceo fue muy dificultosa. Era muy fina y apenas discernible y se encontraba teñida por pigmentos en numerosas e importantes zonas de la pintura. Estos tintes cubrian los fondos, el manto de la Santa Isabel, los espacios entre las figuras de los niños y los mendigos, casi todo el arcón, así como las zonas de sombra del escalón (estratigrafía n 4, p. 30). La diferencia de materiales entre esta capa y la anterior obligó a realizar nuevos test de disolventes. Los primeros hisopos se teñían de color levemente amarillento y posteriormente se teñian de negro, color debido a los humos depositados sobre la obra.

Se realizó una limpieza aún más cuidadosa, ya que estos materiales estaban adheridos a la piel de una pintura muy desgastada por la acción de limpiezas anteriores. Bajo esta capa se encontraron pequeños retoques de óleo en los fondos, deyecciones de insectos, y numerosas faltas de pintura. Estas lagunas -estucadas con una mezcla dura de color gris- tenían el mismo tamaño y forma curvada. Estos deterioros pueden corresponder a un antiguo trabajo de restauración. Al planchar con una plancha de hierro de punta curva, quemaron la superficie de la pintura por exceso de calor. 

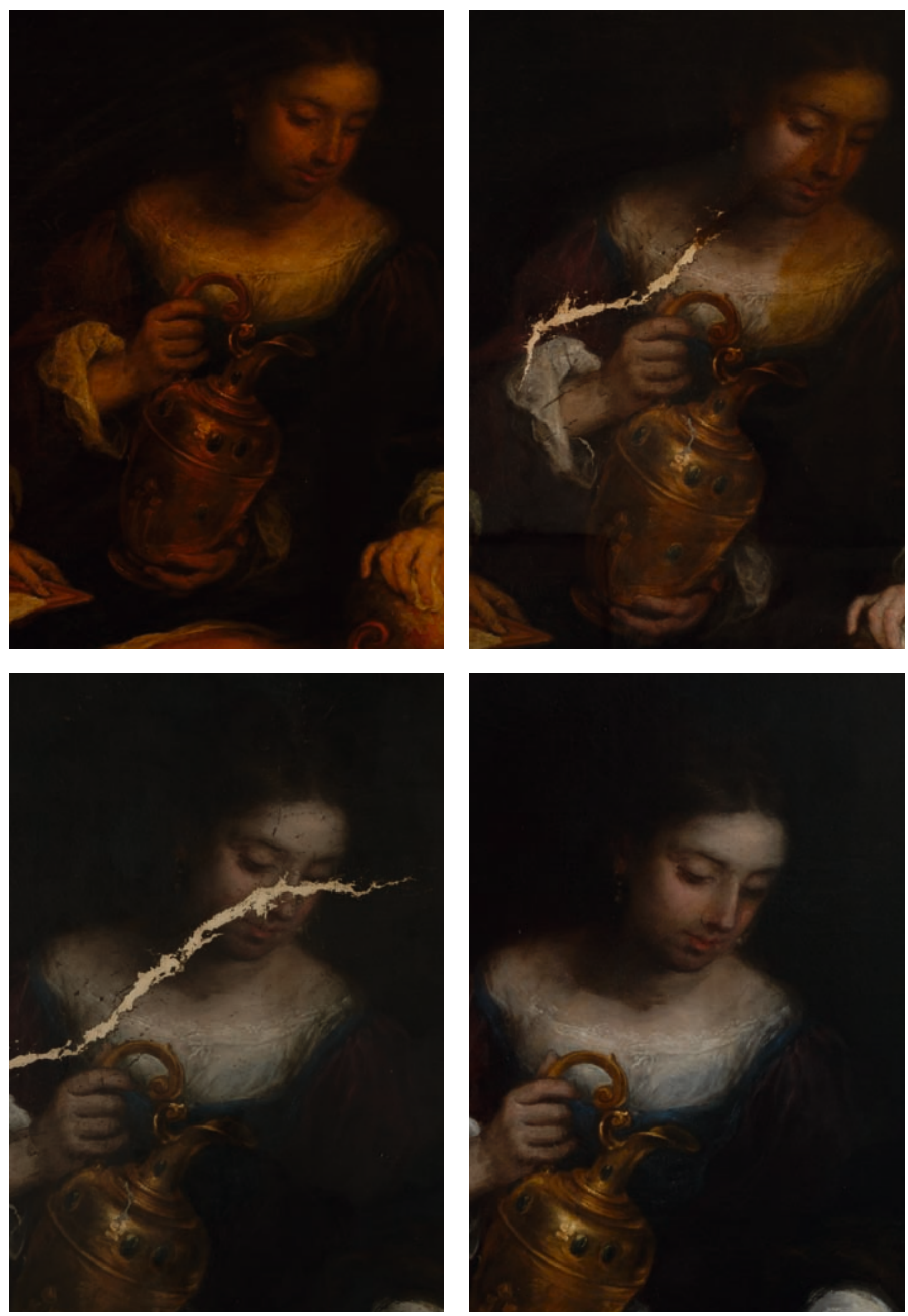

Secuencia del proceso de limpieza. Detalles. Fotos: Eugenio Fernández Ruiz, IAPH 


\section{ANÁLISIS QUÍMICO DE LOS MATERIALES DE LA PINTURA}

Se extrajeron un total de veinticuatro muestras: quince de pintura, tres de estucos, dos de tejidos, tres de barnices y una de papel engomado. El estudio de los materiales utilizados en la ejecución de esta pintura fue realizado mediante las siguientes técnicas:

- Microscopía óptica (Leica DM4000M) para el examen de las estratigrafías y el estudio de las fibras textiles.

- Microscopía electrónica de barrido (JEOL JSM 5600 LV) y microanálisis por dispersión de energía de rayos X (INCA Oxford Instruments) en el análisis de pigmentos y cargas. - Espectroscopia de infrarrojos FT-IR (Nicolet 510P) para el análisis de aglutinantes, barnices y estucos.

\section{Imprimación}

La pintura presenta una preparación ocre terrosa constituida por tierras que contienen óxidos e hidróxidos de hierro y manganeso y blanco de plomo. Superpuestos a la misma se observan, en toda la obra, la presencia de dos estratos de imprimación muy similares al anterior. Existen algunas diferencias estructurales y de composición entre los tres estratos. Esta radica fundamentalmente en la variación de los porcentajes de plomo, silicio, hierro, manganeso y calcio. En cuanto al aspecto, existen pequeñas diferencias de tonalidad entre los mismos.

La composición media elemental de los tres estratos es la siguiente:

\begin{tabular}{lllllllll}
\hline \% peso & $\mathrm{Mg}$ & $\mathrm{Al}$ & $\mathrm{Si}$ & $\mathrm{K}$ & $\mathrm{Ca}$ & $\mathrm{Mn}$ & $\mathrm{Fe}$ & $\mathrm{Pb}$ \\
\hline Capa 1 & --- & 2,2 & 5,3 & 0,3 & 2,8 & 1.9 & 15,7 & 71,8 \\
\hline Capa 2 & 2,8 & 9,7 & 30,7 & 4,9 & 27,2 & --- & 7,9 & 16,8 \\
\hline Capa 3 & 0,1 & 1,2 & 2,9 & 0,4 & 1,7 & 1,1 & 7,1 & 85,5 \\
\hline
\end{tabular}

Las muestras extraídas en la zona del cuadro correspondientes a la intervención del siglo XIX presentan una preparación blanca compuesta por carbonato cálcico.

\section{Capas pictóricas}

\section{Blancos}

El pigmento blanco empleado en la pintura es el blanco de plomo. Este se ha identificado en las capas de color blanco y también mezclado con los demás pigmentos coloreados. El color blanquecino de la manga de la dama de la izquierda está constituido por blanco de plomo, calcita y trazas de carbón y azurita. El blanco del pañuelo del mendigo (muestra extraída de la intervención del siglo XIX) está compuesto por blanco de plomo y trazas de carbón y tierras.

\section{Azules}

El azul verdoso del ropaje de la dama de la izquierda se ha elaborado mezclando blanco de plomo, esmalte, azurita, tierra roja, ocre y calcita. En el caso del vestido de la dama de la jarra, aparece sobre este estrato otro compuesto por blanco de plomo, calcita, azurita, amarillo de plomo y estaño y trazas de tierras. El azul del celaje se ha obtenido mediante dos capas. Sobre una capa de una tonalidad azul grisácea, compuesta por blanco de plomo, negro de carbón, laca roja, tierra roja y trazas de esmalte se superpone una segunda con mayor proporción de esmalte y molido más grueso. El azul del ropaje de la anciana sentada (muestra extraída de la intervención del XIX) está compuesto por blanco de plomo, ocre, tierras, carbón y posible-
Rojos

El rojo del manto de la anciana sentada está constituido por una capa de color pardo rosado compuesta por blanco de plomo, laca roja, sombra y calcita. Superpuesta se observa una capa de color rojo intenso compuesta por abundante bermellón mezclado con blanco de plomo, laca roja y tierra roja. El rojo de la cortina esta constituido por laca roja, tierra roja y negro de carbón. El rojo de la parte inferior del manto de la mendiga, correspondiente a la intervención de XIX, presenta dos estratos: el inferior, constituido por blanco de plomo y tierra roja y el superior, por blanco de plomo, bermellón y tierra roja.

Grises

El gris oscuro del fondo presenta dos estratos superpuestos. El inferior, de color gris oscuro, está compuesto por blanco de plomo, tierras, ocre, azurita, esmalte, sombra y trazas de laca roja. El superior, gris azulado, está constituido por blanco de plomo, tierras, azurita y ultramar. El gris del fondo de la intervención del XIX está compuesto por blanco de plomo, tierras y carbón.

\section{Carnación}

La muestra extraida del brazo del niño presenta una gruesa capa de color rosado compuesta por blanco de plomo, bermellón, ocre y tierra roja y dos finas capas discontinuas compuestas por blanco de plomo, tierra roja y ocre.

\section{Amarillos y dorados}

El ocre del arcón presenta una capa discontinua de coIor rojizo compuesta por blanco de plomo, tierra roja y bermellón. Superpuesta se observa una capa discontinua de color ocre terroso compuesta por ocre, tierras y blanco de plomo. El dorado de la decoración (muestra extraída de la intervención del XIX) está constituido por una finísima capa de oro aplicada sobre una capa de color ocre compuesta por blanco de plomo y ocre.

Los pigmentos identificados han sido los siguientes: Blancos: blanco de plomo, calcita Rojos: tierra roja, bermellón, laca roja

Pardos: tierras, sombra

Azules: azurita, esmalte, ultramar, azul de Prusia

Amarillos: amarillo de plomo y estaño, ocre

Metálicos: oro

Negros: carbón

\section{Barnices}

A partir de las muestras extraídas con ayuda de un hisopo impregnado en etanol en tres puntos distintos de la obra se determinó, mediante espectrometría infrarroja, la composición del barniz. Se trata de una resina natural triterpénica, posiblemente almaciga.

El análisis mediante microespectrometria FTIR de la imprimación revela, además de la presencia de carbonatos y silicatos, compuestos oleosos y proteínicos.

En las capas pictóricas se han identificado compuestos oleosos y proteínicos.

\section{Estucos}

La mayoría de los estucos analizados son de carbonato cálcico. Sólo uno de ellos es de sulfato cálcico.

\section{Soporte}

El tejido original y el empleado en el reentelado son de lino.

\section{Aglutinantes}

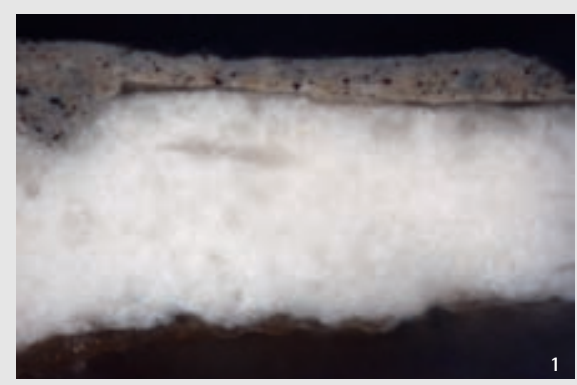

Sección transversal del gris del fondo. Foto: Lourdes Martín

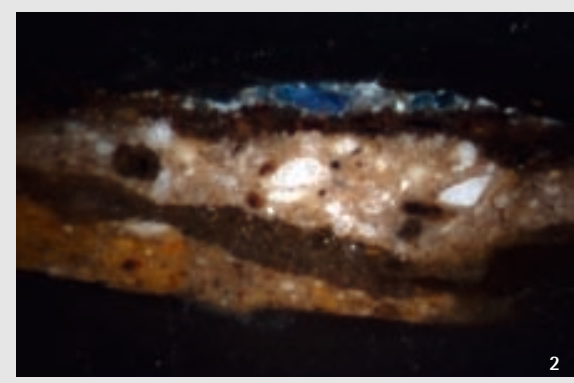

Sección transversal del azul del vestido de la dama de la jarra. Foto: Lourdes Martín

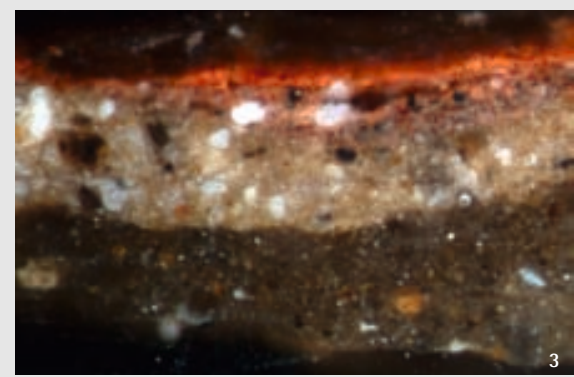

Sección transversal del rojo del manto de la anciana sentada. Foto: Lourdes Martín

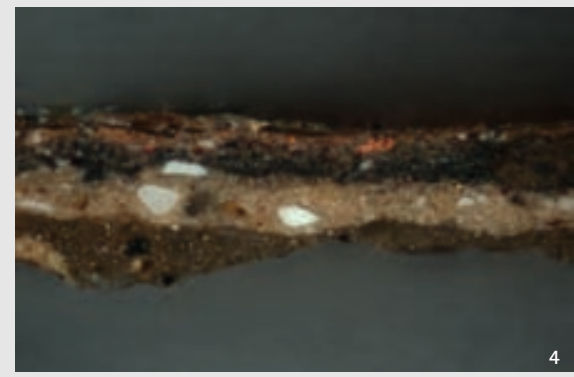

Sección transversal del ocre del arcón. Foło: Lourdes Martín

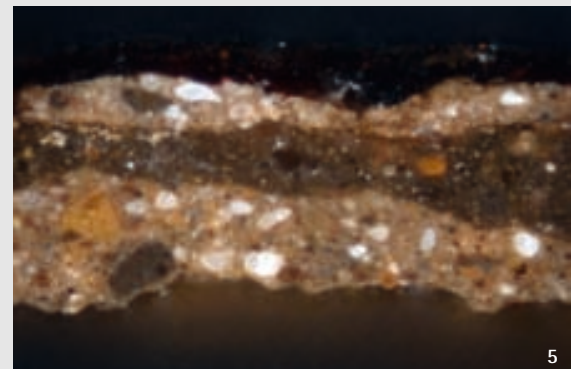

Sección transversal del rojo de la cortina. Foto: Lourdes Martín

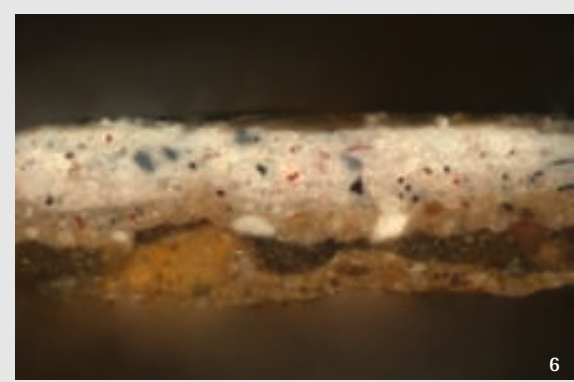

Sección transversal del azul del celaje. Foto: Lourdes Martín 


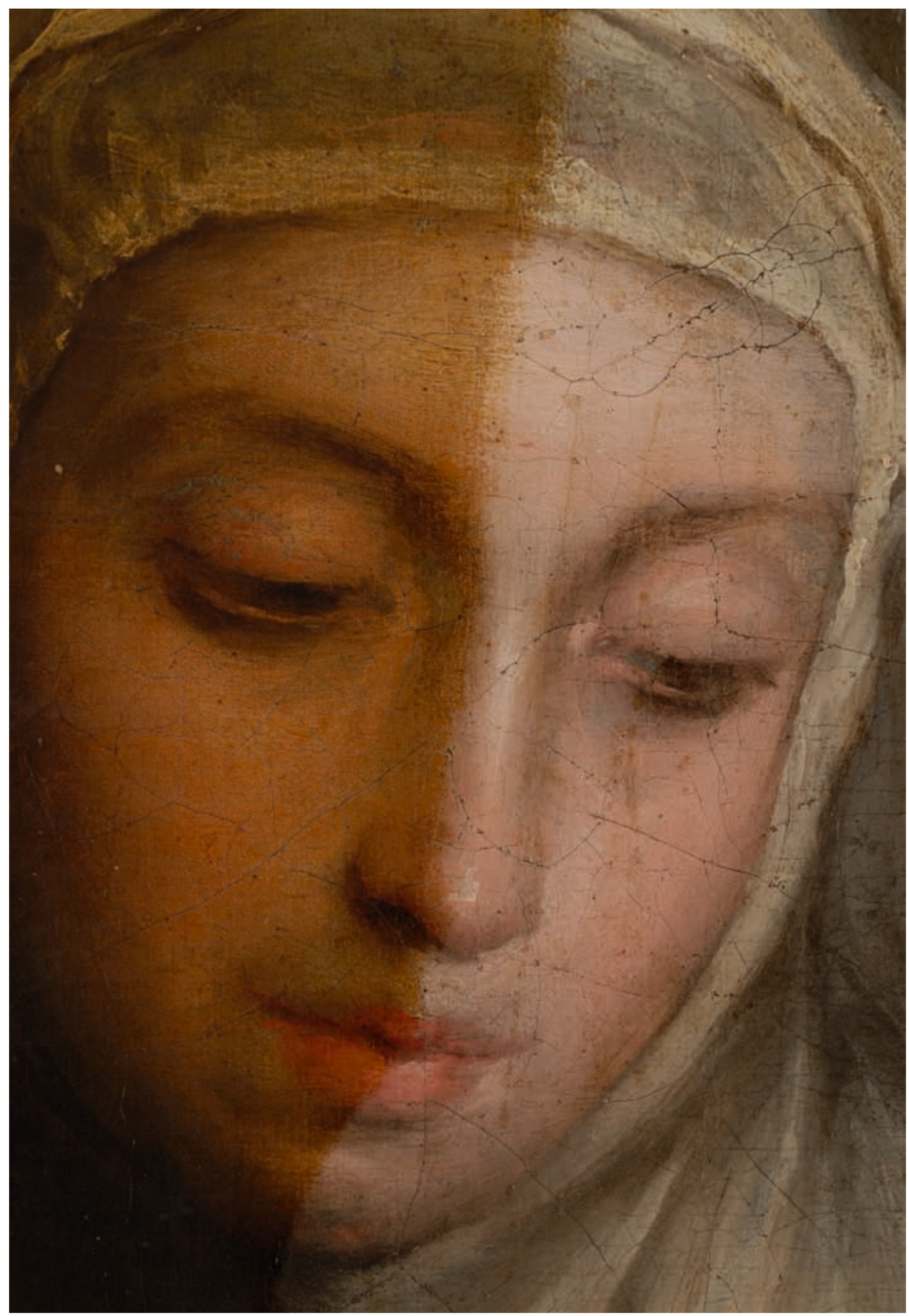

Proceso de limpieza. Desgaste de las cejas de la superficie pictórica. Foto: Eugenio Fernández Ruiz, IAPH 


\section{EL ESTILO PICTÓRICO DE MURILLO}

Solamente después de finalizar la segunda fase de limpieza se percibieron los detalles más delicados y se estudió en profundidad la forma en que la obra fue ejecutada.

La pintura está realizada al óleo sobre varios estratos de imprimación de color terroso oscuro, aglutinados con aceite. La última capa de imprimación se percibe de forma muy importante en toda la superficie dándole a la obra una entonación grisácea. En algunas áreas realizadas con tonos claros la pintura se ha hecho transparente al envejecer y a través de ella se percibe la imprimación con claridad. También los desgastes existentes en los bordes de los grandes craquelados permiten la observación de este estrato. Estas capas de color están ejecutadas con una clara intención pictórica. En algunas áreas el autor ha utilizado el óleo muy diluido dejando a la vista el fondo, alli donde le interesa. En los celajes se puede apreciar la entonación gris bajo los blancos azulados extendidos con pinceles anchos.

Otro detalle a destacar en la ejecución pictórica de Murillo es la forma en que ejecuta los espacios que quedan entre las figuras. Al tener una imprimación adecuada a la entonación general del cuadro, las grandes pinceladas de los fondos no se acercan del todo a los bordes de las figuras por lo que las formas quedan sueltas, creándose entre todos los elementos compositivos una atmósfera muy característica.

Este efecto se puede observar de forma muy clara en el espacio comprendido entre el niño que se rasca la cabeza y el mendigo de la muleta. El fondo oscuro entre ambas figuras apenas ha sido pintado, quedando la base a la vista. El brazo y la mano de la figura masculina están dibujados con unas líneas realizadas con un fino pincel, para de esta forma definir el borde del brazo y de la mano, destacándolos del fondo.

La pintura está realizada en muchos espacios alla prima con sólo una capa, como es el caso del cortinaje carmín oscuro (véase estratigrafía no 5 , p. 30). Casi todas las muestras analizadas tienen dos estratos de pintura, en algunos casos realizados en fresco como puede comprobarse en la estratigrafía de la muestra tomada de los celajes claros (véase estratigrafía $n^{\circ} 6$, p. 30). Como se ha comentado con anterioridad, algunas pinceladas delicadas que definian detalles de los rostros como, en el caso de la Santa Isabel, las cejas o los labios, se encuentran muy desgastadas por limpiezas anteriores.

La obra de Murillo es una pintura muy natural, tanto en su contenido como en su ejecución, no encontrando en ambos casos elementos retóricos que distraigan de lo esencial: la descripción pictórica de una escena. Precisamente, en esta simplicidad aparente radica la dificultad de estudiar de forma pormenorizada los elementos que constituyen la pintura para poder acometer el trabajo de restauración respetando absolutamente un original cuya superficie ha sido tan maltratada.
En general, se puede afirmar que esta obra de madurez de Murillo reúne tanto compositiva como técnicamente la maestría con que el pintor trabajaba. También sintetiza su obra anterior, pues en ella se manifiestan las formas de trabajar ya observadas en otras obras magistrales del autor. Así, por ejemplo, se puede establecer una clara relación entre los niños aquí representados con los de las pinturas de género. Concretamente la obra Comedores de pasteles, Alte Pinakothek (Munchen), ejecutada entre 1670 y 1675, presenta grandes coincidencias con esta obra, también ejecutada por Murillo en su época tardiå

\section{Arrepentimientos}

Aunque el dibujo de la composición pictórica es muy preciso, se han encontrado modificaciones de poca importancia observadas a simple vista tras la fase de limpieza, que no son visibles en las radiografías debido al uso de blanco de plomo tanto en la capa de imprimación como en la ejecución de la pintura.

En la zona alta de la obra, en la parte correspondiente a la arquitectura, se ha observado que en principio existía una figura togada situada sobre un pequeño pedestal que remataba la balaustrada. Ambos fueron, posteriormente, cubiertos por paramentos lisos de color claro, cambiando totalmente la composición. Al realizar este cambio, los celajes situados alrededor de la escultura, pueden observarse fácilmente a través de la capa definitiva, realizada con menos empaste.

Las otras dos modificaciones están situadas en la mitad inferior de la obra. El paño rojo de los ropajes de la anciana ocupaba más espacio sobre el suelo. Quedó limitado al situar sobre él los trazos que componen la pierna de la figura del mendigo con muletas. El color rojizo se manifiesta claramente a través de los tonos tierras. También el suelo cercano a esta zona tiene un color gris ligeramente rosado debido, con probabilidad, a la mezcla azarosa del bermellón con los colores utilizados para elaborar los grises del suelo. Otra pequeña rectificación se ha observado en la toca blanca que cubre la cabeza de este personaje femenino.

\section{REINTEGRACIÓN CROMÁTICA}

Al eliminar todos los materiales añadidos quedó a la vista la pintura original con los estucos blancos y grises que se habían conservado y la interpretación del siglo XIX sin añadidos.

En la fase de limpieza se utilizaron los calcos realizados a la radiografía para de esta forma recuperar los retazos de original que estaban ocultos y que sirvieran como referencias de color. El pie izquierdo del mendigo, burdamente representado, fue mejorado gracias a unos fragmentos de la alpargata original que estaban cubiertos por carnaciones. Este pie era más grande que el otro. Liberando estos pequeños fragmentos de pintura original, se 


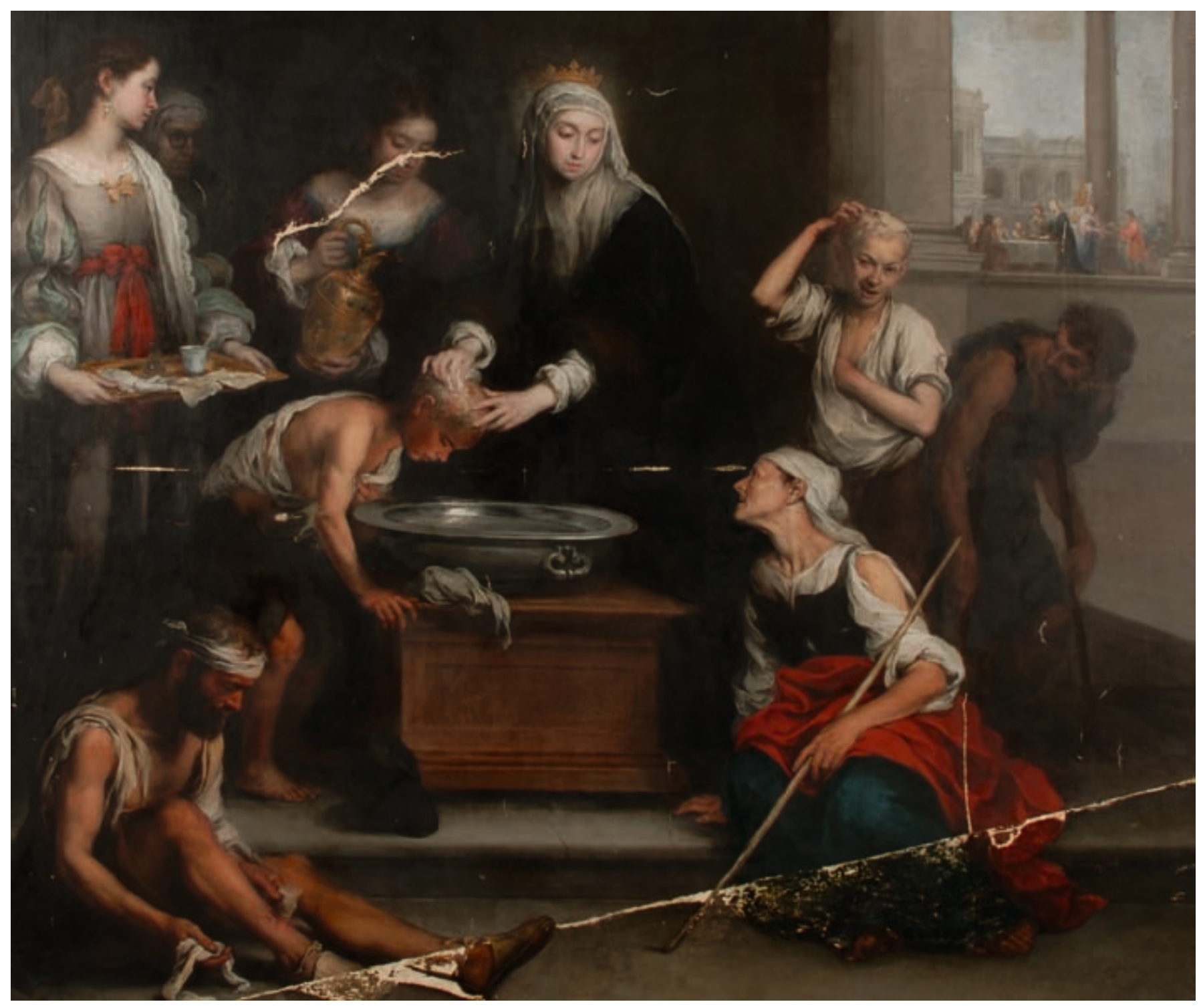

Detalle central finalizada la limpieza. Puede apreciarse la diferencia tonal entre ambas zonas y el testigo de la segunda fase de limpieza. Foto: Eugenio Fernández Ruiz, IAPH

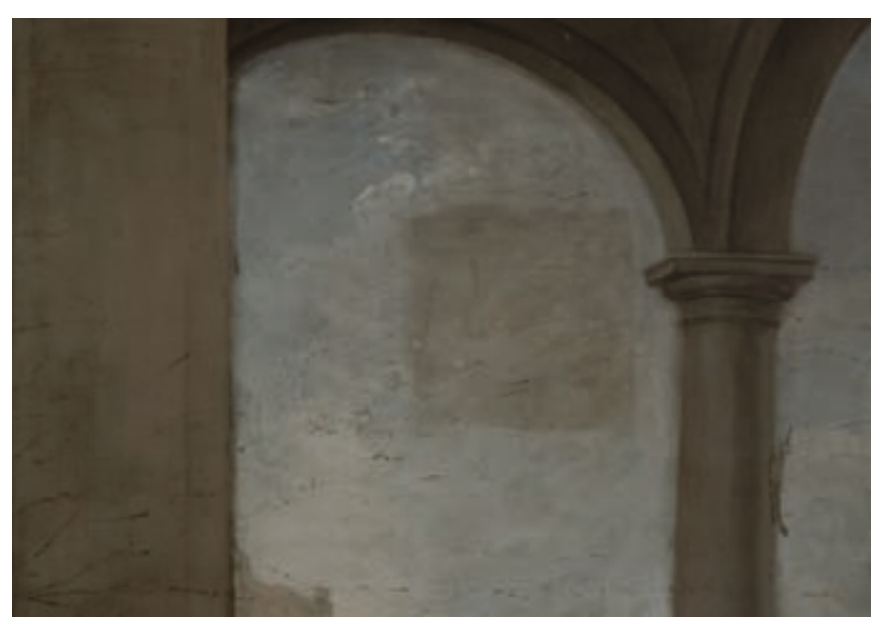

Testigo de la segunda fase de limpieza. Foto: Eugenio Fernández Ruiz, IAPH

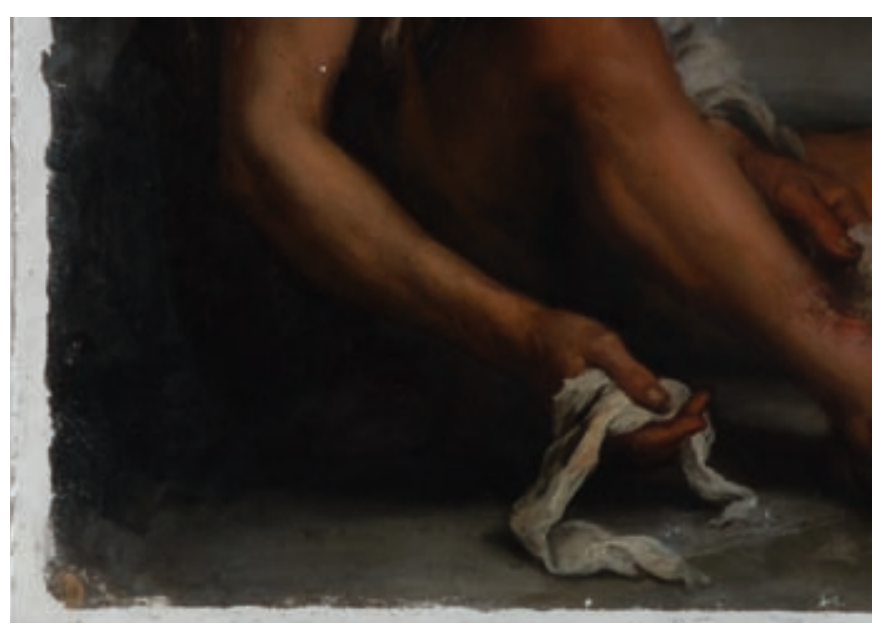

Fase de estucado y restos de etiqueta. Foto: Eugenio Fernández Ruiz, IAPH

El estudio de los distintos materiales encontrados durante

el proceso de restauración ha permitido establecer el número de intervenciones realizadas 

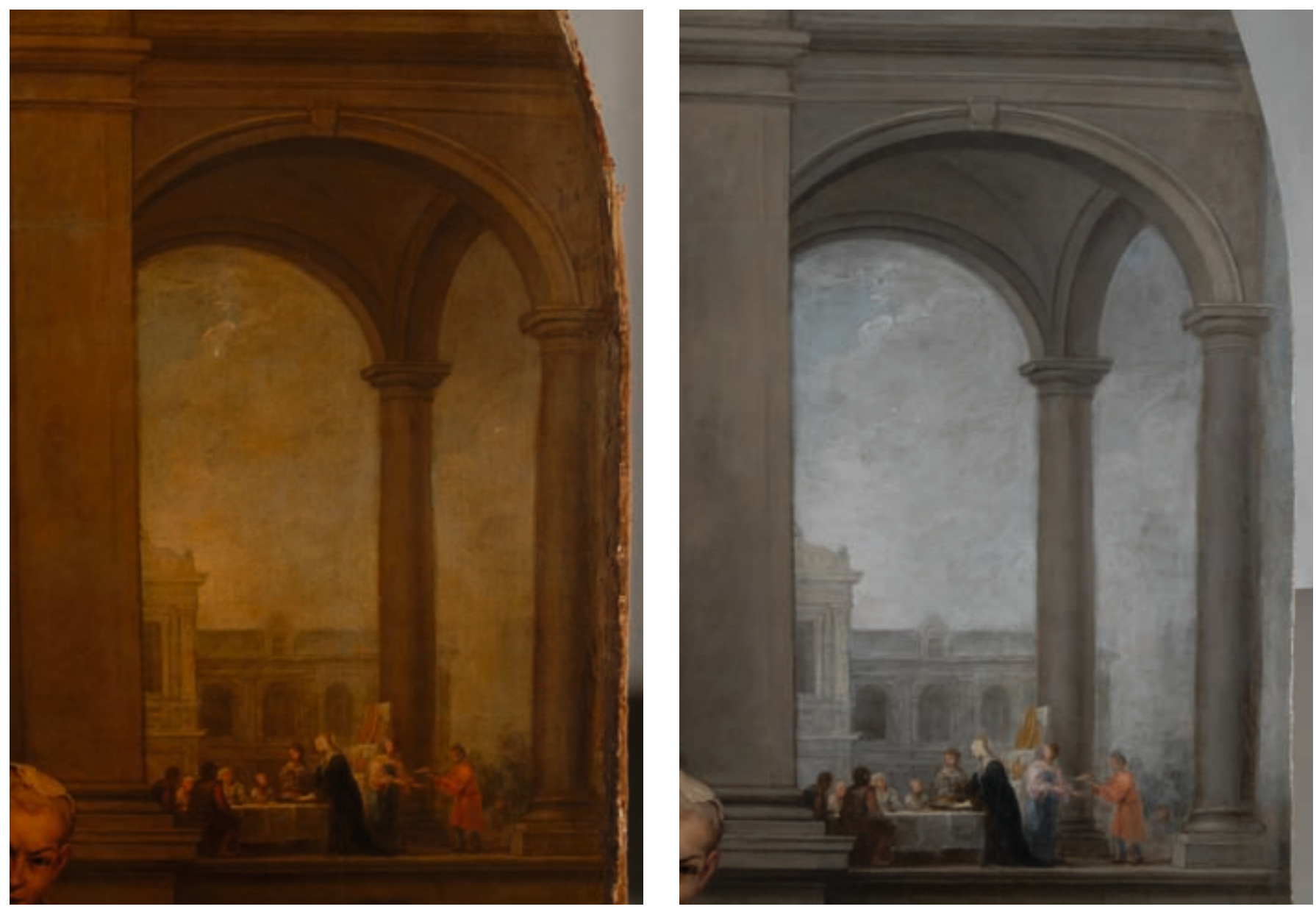

Estados inicial y final. Detalle de la escena de segundo plano de la obra. Fotos: Eugenio Fernández Ruiz, IAPH
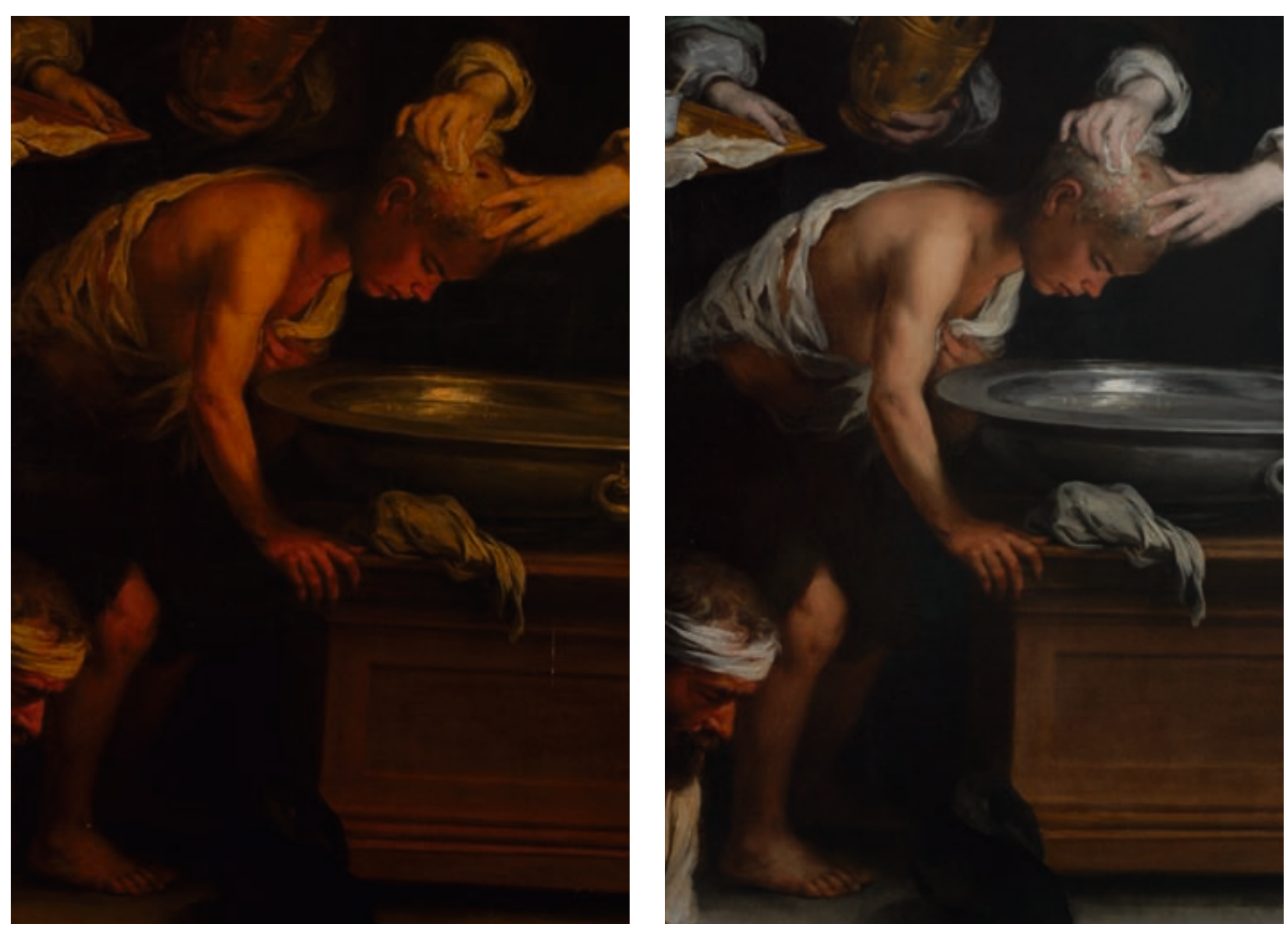

Estados inicial y finalizada la intervención. Fotos: Eugenio Fernández Ruiz, IAPH 


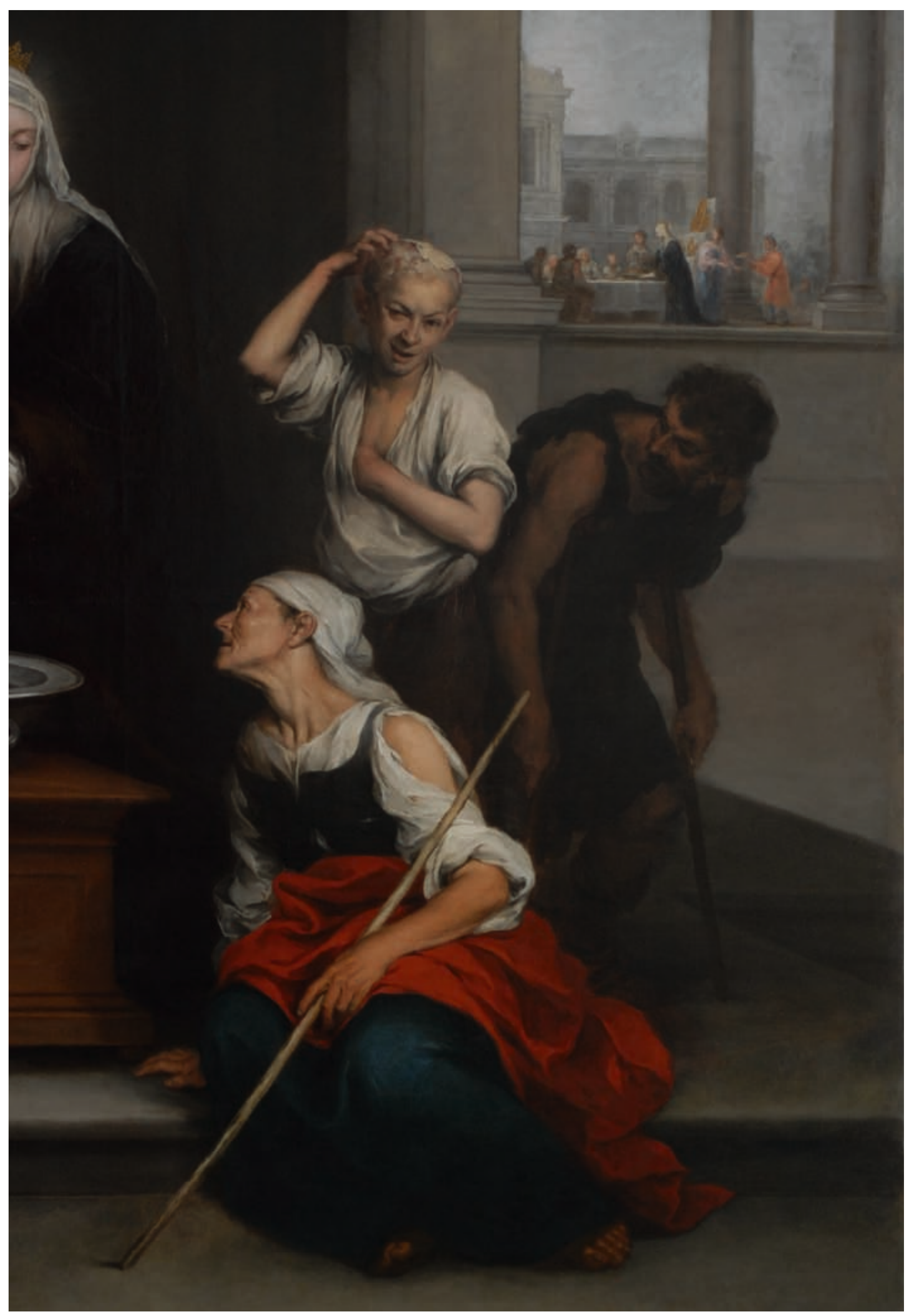

Estado final de la obra tras la intervención. Detalle. Foto: Eugenio Fernández Ruiz, IAPH 


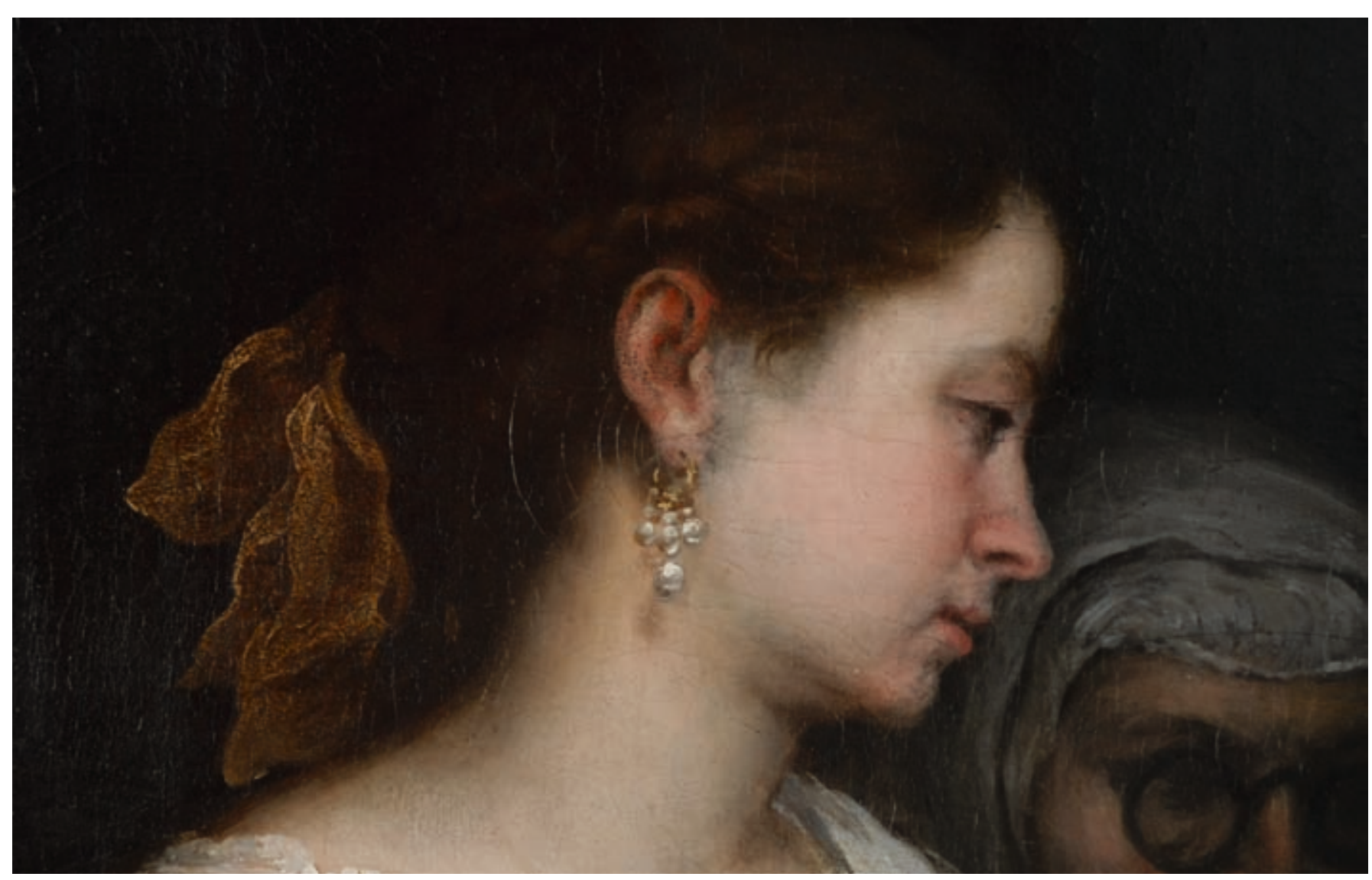

Detalle de la obra tras la intervención. Foto: Eugenio Fernández Ruiz, IAPH

mejoró toda esta zona sin intentar en ningún momento volver a reinterpretar el original de Murillo. También durante la limpieza se habian recuperado pequeños fragmentos rojos y azules de las ropas de la anciana; así como del suelo y del bastón.

La primera parte del trabajo se realizó con acuarelas sobre las preparaciones blancas de anteriores restauraciones. Se utilizó, rigurosamente, la técnica de rigattino, ya que las líneas verticales eran las más adecuadas para adaptar ambas zonas. Una vez finalizada esta primera fase de reintegración cromática, la obra se barnizó a mano con brocha. Seguidamente se estucaron todas las zonas que carecian de preparación. El tejido original de los dos bordes laterales y del borde inferior, así como partes de los ángulos y pequeñas lagunas del medio punto y de las costuras, se prepararon con un estuco blanco elaborado con sulfato cálcico y cola animal.

La segunda fase de reintegración cromática consistió en la reintegración con acuarelas de los nuevos estucos con la misma técnica utilizada en la fase anterior. Se volvió a barnizar a mano toda la superficie de la pintura y sobre este barniz se finalizó el trabajo con pigmentos al barniz. La diferencia tonal entre ambas zonas se había atenuado con las acuarelas pero aún era evidente. Para poder adecuar de forma correcta una pintura de mala calidad con otra de excelente factura fue preciso trabajar unos $2 \mathrm{~cm}$ sobre el borde de la pintura falsa e ir degradando el color hacia abajo para eliminar la dureza de la línea de separación.

\section{METODOLOGÍA Y CRITERIOS DE INTERVENCIÓN}

La metodología de trabajo empleada en el desarrollo de este proyecto ha tenido un carácter interdisciplinar. En todo momento las distintas fases del proyecto se han adptado a los protocolos de actuación del Centro de Intervención del IAPH. La aplicación de esta metodología se ha basado principalmente en dos principios fundamentales: el respeto absoluto a la singularidad de este bien, cuya intervención estaba plenamente justificada, y la adopción del principio de mínima intervención.

En el caso de esta pintura, este último principio se ha llevado a cabo de una forma exhaustiva. En la fase de limpieza, respetando aquellas intervenciones anteriores que presentaban un buen estado de conservación; en la fase de reintegración cromática, adecuando tonal y matéricamente dos espacios claramente diferenciados: una magnífica pintura de gran formato del siglo XVII y un fragmento de pintura de mala calidad del siglo XIX.

Los materiales empleados han sido análogos a los originales y reversibles. De esta forma se contribuye a las futuras necesidades conservativas del bien. La obra Santa Isabel de Hungría curando a los tiñosos entró en las dependencias del Centro de Intervención del IAPH en noviembre de 2006.Tras la finalización del proyecto en julio de 2008 la obra no se montó en su emplazamiento habitual ya que formó parte de la exposición Ilustración y liberalismo en América y España, 1788-1814, celebrada en El Palacio Real de Madrid, desde el día 17 de octubre de 2008 hasta el 10 de enero de 2009. La pintura quedó colocada en su altar original el día 15 de enero de 2009. 


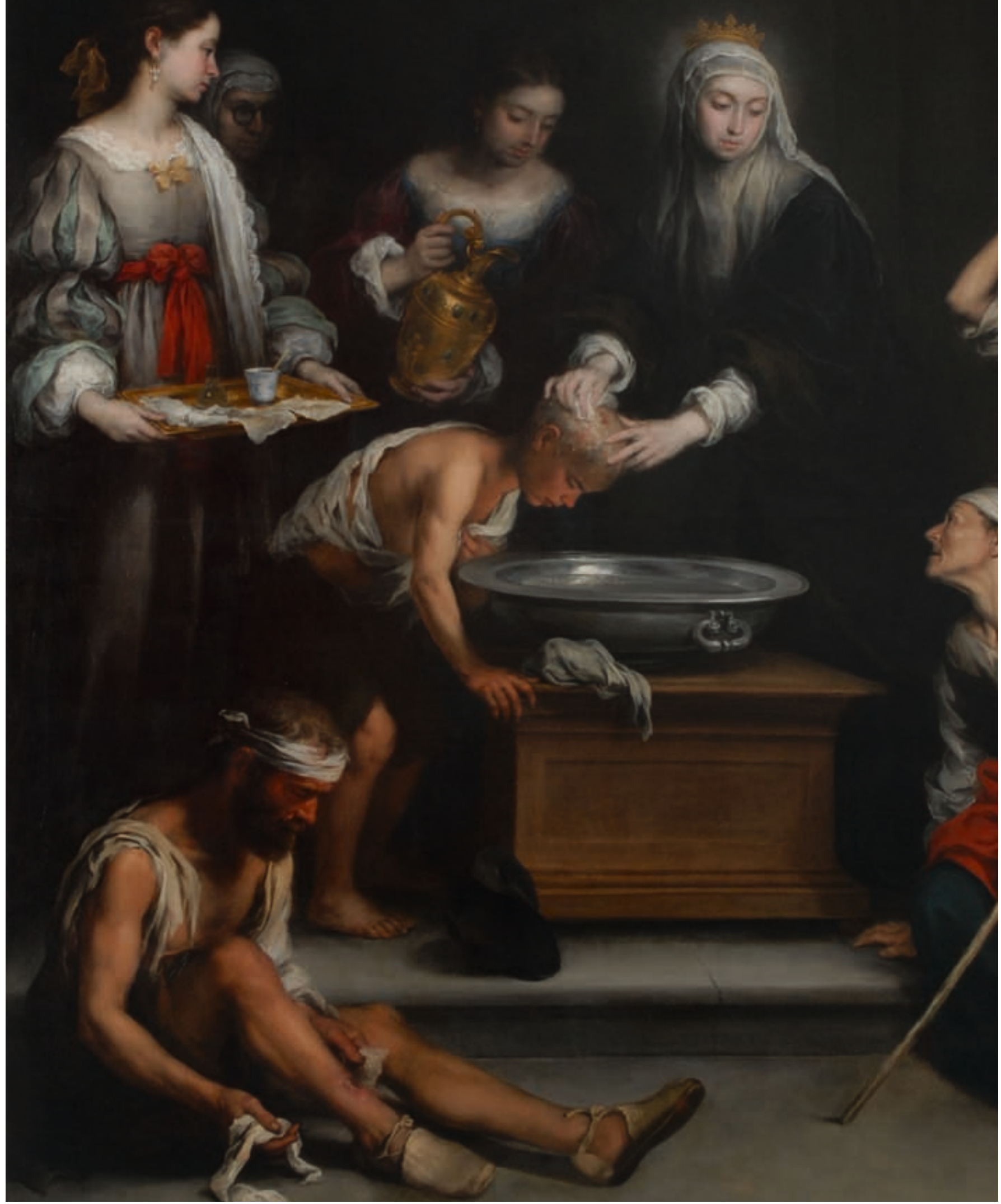

Estado final. Foto: Eugenio Fernández Ruiz, IAPH 


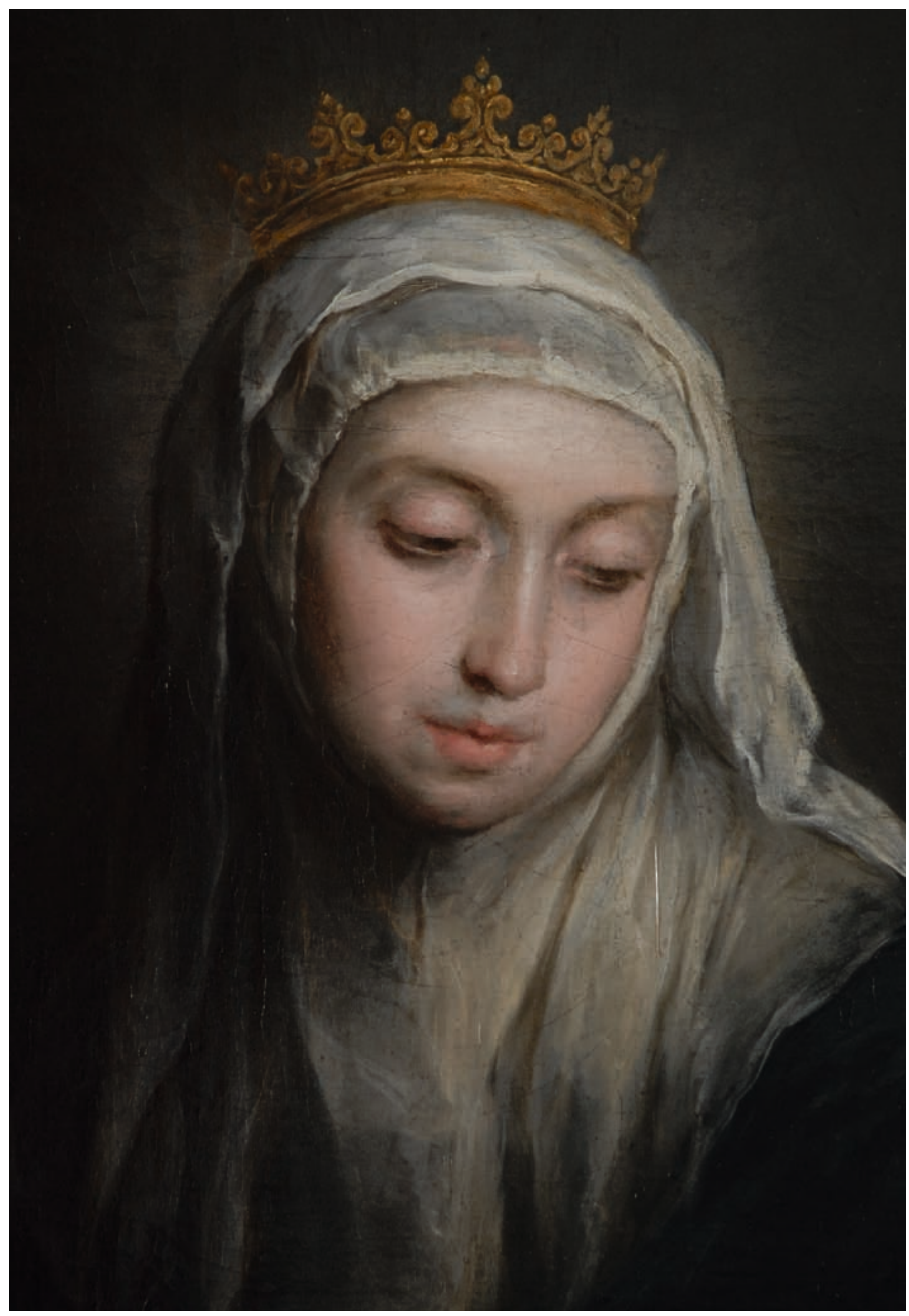

Estado final tras la intervención. Foto: Eugenio Fernández Ruiz, IAPH 
${ }^{1}$ Archivo Hermandad de la Santa Caridad. Libro II de Cabildos, que cubre el período de 10 de enero de 1672 a 28 de diciembre de 1676. También se menciona la pintura en el balance financiero de fin de año, el 28 de diciembre de 1672

${ }^{2}$ CRUZ Y BAHAMONTE, 1813: 240-241. Cita del autor hacia 1803: "Aqui se hallan actualmente las copias que está sacando Cortés de orden del Rey de los cuadros de la caridad de Murillo, con inteligencia y gusto". (La copia de Santa Isabel de Hungría curando a los tiñosos de Joaquín $\mathrm{M}^{\text {a }}$ Cortés se encuentra en la actualidad en el Palacio de Oriente con el $n^{\circ}$ de inventario 10016154).

${ }^{3}$ FERNÁNDEZ PARDO, F. Dispersión y destrucción del Patrimonio Artístico Español (1808-1814). Guerra de la Independencia. Madrid, 2007. Punto $2^{\circ}$ de la Real Orden de 20 de Diciembre de 1809.

${ }^{4}$ ANGULO î̃IGUEZ, D. Murillo. Madrid, 1981. Inventario de los cuadros sustraídos por el gobierno intruso en Sevilla, que elaborara Gómez Imaz, quien da noticias a respecto tras ser depositado en el Alcázar de Sevilla por los franceses constando con el número 1 de la primera sala. Se llegaron a reunir 999 cuadros de toda SeviIla, que se inventariaron y organizaron por salas.

${ }^{5}$ Cartas de 26 de febrero y 26 de octubre de 1939 de Joaquín Romero Murube al Hermano Mayor

${ }^{6}$ Rafael Sadeler (Amberes 1584-Múnich 1632). Grabador flamenco descendiente de una amplia saga de grabadores activa en Bélgica, Alemania e Italia. Trabajó en Venecia bajo la dirección de su padre y maestro, Rafael Sadeler el Viejo, desde 1596 a 1604. Desde 1610 a 1632, fecha en que le sorprende la muerte, trabaja en los grabados del Bavaria Sancta, en los cuales reproduce dibujos de Mathias Kager.

${ }^{7}$ Bavaria Sancta. Libro encargado por los Duques de Baviera en el que se recoge la hagiografia bávara. Fue realizado entre 1615 y 1627 por el jesuita Matheus Rader e incluye grabados realizados por Rafael Sadeler el Viejo y Rafael Sadeler el Joven a partir de dibujos de Mathias Kager.

${ }^{8} \mathrm{~V}$. Sonnenburg. Acerca de la Técnica pictórica de Murillo. En la descripción de la ejecución pictórica de esta obra de género de Murillo, que fue realizada a través de las aportaciones científicas de Frank Preuber, se han observado claras similitudes con la técnica pictórica de la obra Santa Isabel de Hungría curando a los tiñosos.
ANGULO íñIGUEZ, D. (1981) Murillo. Su arte, su vida, su obra (Tomo I). Madrid : Espasa Calpe, 1981

BROWN, J. (1988) Imágenes e ideas en la pintura española del siglo XVII. Madrid : Alianza, 1988

BRUQUETA GALÁN, R. (2000) Técnicas y materiales de la pintura española en los siglos de oro. Madrid: Fundación de Apoyo a la Historia del Arte Hispánico, 2000 CRUZ Y BAHAMONTE, N. (1813) Conde de Maule. Viaje de España, Francia e Italia.Tomo XIV. Cádiz, 1813

GAYA NUÑO, J. A. (1978) Clasici dell'arte. L'opera completa de Murillo. Milano : Rizzoli Editore, 1978

GUERRERO LOVILLO, J. (1952) Murillo y Assereto. Los grabados que inspiraron la Santa Isabel de Murillo. Madrid : Archivo español de arte, 1952

LAFUENTE, M. (1980) Historia de España (Tomo XVI). Barcelona : Montaner y Simón Editores, 1980

MORENO ALONSO, M. (1995) Sevilla Napoleónica. Sevilla : Ediciones Alfar 1995

NAVARRETE PRIETO, B. (1998) La Pintura Andaluza del siglo XVII y sus fuentes grabadas. Madrid : Ed. Fundación de Apoyo a la historia del arte hispánico, 1998 POOLE DE LIÑÁN, J.M. (2005) Originales y copias: Vicisitudes de las pinturas de la Hemandad de la Santa Caridad de Sevilla. Sevilla : Hospital de la Santa Caridad, 2005

RÉAU, L. (1997) Iconografia del Arte Cristiano. Iconografia de los Santos (de la G a la O). Barcelona : Ed. Serbal, 1997

SERRERA, J. M. (1988) Varia Murillesca. Archivo Hispalense, n. 218, Sevilla, 1988

SANTO TOMÁS PÉREZ, M. (1998) Santa Isabel bañando a los tiñosos. Análisis iconográfico. Rev. Index de Enfermería (edición digital). Valladolid, 1998 W.AA. (2001) José Villegas (1844-1921). Catálogo. Córdoba : Obra Social y Cultural de Cajasur, 2001

VALDIVIESO, E. ; SERRERA J. M. (1980) El Hospital de la Santa Caridad de Sevilla. Sevilla: Edic. de los autores, 1980

\section{INSTITUTO ANDALUZ DEL PATRIMONIO HISTÓRICO}

Recuperación de una obra de Bartolomé Esteban Murillo:

Santa Isabel de Hungría curando a los tiñosos

\section{Román Fernández-Baca Casares}

Director del IAPH

Lorenzo Pérez del Campo

Jefe del Centro de Intervención

Conservación - restauración

Amalia Cansino Cansino
Estudio histórico-artístico

Gabriel Ferreras Romero

Radiografías y fotografías

Eugenio Fernández Ruiz
Colaboradores:

Macarena Bargalló Pérez

Estancia de prácticas de pintura

Inmaculada Sánchez Romero

Estancia de prácticas de química
Análisis químicos

Lourdes Martín García 